\title{
Civic Virtue and Labor Market Institutions ${ }^{\dagger}$
}

\author{
By Yann Algan and Pierre Cahuc*
}

\begin{abstract}
We argue civic virtue plays a key role in explaining the design of public insurance against unemployment risks by solving moral hazard issues which hinder the efficiency of unemployment insurance. We show, in a simple model, that economies with stronger civic virtues are more prone to provide insurance through unemployment benefits rather than through job protection. We provide cross-country empirical evidence of a strong correlation between civic attitudes and the design of unemployment benefits and employment protection in OECD countries over the period 1980 to 2003. We then use an epidemiological approach to estimate the existence of a potential causal relationship from inherited civic virtue to labor market insurance institutions. (JEL: J41, J65, J68, Z13)
\end{abstract}

long tradition has emphasized civic virtue in explaining political institutions. In the Republic, Plato argued that governments vary in accordance with the dispositions of their citizenry. In Democracy in America, Alexis de Tocqueville argued that civic behavior is essential for stable and effective democratic institutions. More recently, Gabriel A. Almond and Sidney Verba (1963) attempted to explain differences in democratic governance in the United States, Great Britain, Italy, Mexico, and Germany through a set of political attitudes and orientations grouped under the rubric of civic culture. Robert D. Putnam (1993) argued, in an influential comparative study of regional governments in Italy, that the success of democracies depends in large part on civic virtue. As far as we know, this line of inquiry has not been used to analyze the influence of civic virtue on labor market institutions. This is quite surprising, as one important goal of labor market institutions is to provide insurance, the design of which might be influenced by civic virtue. 1

In our paper, we argue that civic virtue plays a critical role in explaining the design of the main public insurance institutions of the labor market: unemployment benefits and employment protection. We are able to measure civic attitudes in a

\footnotetext{
* Algan: Paris School of Economics, Paris East University, IZA, 48 boulevard Jourdan, 75014 Paris, France, (e-mail: yann.algan@ens.fr); Cahuc: Ecole Polytechnique, 15 Boulevard Gabriel-Peri, 92245 Malakoff, France, CREST, CEPR, and IZA (e-mail: cahuc@ensae.fr). We thank the editor, Olivier Blanchard, for his key help in improving this article, and the two anonymous referees for their very helpful comments. We also thank Giuseppe Bertola, Christopher Carroll, Bruno Decreuse, Thomas Philippon, Fabien Postel-Vinay, Robert Putnam, Richard Rogerson, Till von Wachter, and André Zylberberg for very helpful remarks. We thank participants in seminars at the 2005 IZA Price Conference in Berlin, at Columbia University, at Paris School of Economics, and at the IZA workshop on job protection and labor markets. The usual disclaimer applies.

${ }^{\dagger}$ To comment on this article in the online discussion forum visit the articles page at: http://www.aeaweb.org/articles.php?doi=10.1257/mac.1.1.111

${ }^{1}$ The role of beliefs and values on economic outcomes is of growing interest in the economic literature. For instance, cultural differences turn out to have an impact on financial development (Luigi Guiso, Paola Sapienza
} 
precise (but narrow) way by using the following question in international social surveys: "Do you think it can always be justified, never be justified, or something in between to claim government/state benefits to which you have no rights." We show that cross-country differences in unemployment benefits and employment protection legislation are influenced deeply by differences in the answers to this question across countries. We show that this influence still holds when we use other indicators of civic attitudes, such as indicators of trustworthiness and trust.

The relationship between civic virtue, unemployment benefits, and job protection is then derived in a simple model (presented in Section I) in which unemployment benefits and job protection are shaped by a government ${ }^{2}$ that maximizes a social welfare function. This model shows that the provision of unemployment insurance is more costly in economies in which civic attitudes make it more acceptable to cheat on unemployment benefits, leading the government to provide lower unemployment benefits. ${ }^{3}$ In this case, the government provides insurance by using a less efficient institution-employment protection. Moral hazard thus hampers the government's ability to implement efficient insurance institutions 4

In Section II, we use international individual surveys to document the cross-country heterogeneity in civic values across Organization for Economic Co-operation and Development (OECD) countries during the period 1980-2003. Two polar cases show up. The first one is made up of Nordic countries and, to a lesser extent, AngloSaxon countries, in which the majority of the population finds it unjustifiable to cheat on government benefits. At the other extreme stand Latin American and Mediterranean countries where the majority of the population would not blame such

and Luigi Zingales 2004), fertility rates (Raquel Fernández, Alessandra Fogli, and Claudia Olivetti 2004, Fernández and Fogli 2005), employment rates (Algan and Cahuc 2005, Fernández and Fogli 2005), and on individuals' prior on social mobility (Alberto Alesina and Edward L. Glaeser 2004). In the same spirit, the paper of Andrea Ichino and Giovanni Maggi (2000), which documents the existence of north-south regional differences in regard to shirking of responsibility in a large Italian bank, suggests that civic culture is influenced by individuals' historical heritage. This literature also stresses that the degree of trust or civicmindedness has a direct impact on economic development and growth as suggested by Algan and Cahuc (2007), Guido Tabellini (2005), and Stephen Knack and Philip Keefer (1997). The importance of civic culture and trust was first explored in sociology and political science by Edward C. Banfield (1958) and Putnam (1993).

${ }^{2}$ In the seminal papers of the "implicit contract" (Martin Neil Baily 1974 and Costas Azariadis 1975), unemployment insurance is provided by employers. However, in the real world, unemployment insurance is always provided by government or public agencies and not by firms because selection and moral hazard problems make it impossible for firms to provide unemployment benefits directly (Jaakko Kiander 1993, W. Henry Chui and Edi Karni 1998). When unemployment insurance is provided by public authorities, it is worth introducing employment protection, in the form of layoff taxes, to induce firms to take account of the fiscal externalities linked to their job destruction decisions (Martin S. Feldstein 1976; Kenneth Burdett and Randall Wright 1989a,b; Olivier Blanchard and Jean Tirole 2004).

${ }^{3}$ Tito J. Boeri, Igniacio Conde-Ruiz, and Vincenzo Galasso (2004) also provide a model that exhibits a tradeoff between unemployment benefits and job protection. However, the trade-off stems from distributional conflicts between high-skilled and low-skilled workers.

${ }^{4}$ The role of preferences and values in shaping labor market outcomes is of growing interest in the literature. Richard B. Freeman (2000) argues that diversity of labor market institutions among advanced countries stems from cross-country differences in preferences for redistribution. Other contributions have claimed that differences in labor market institutions and outcomes are rooted in the higher weight put on home production in European countries (Richard Rogerson 2003, Freeman and Ronald Shettkat 2005), come from stronger preferences for leisure (Blanchard 2004; Alesina, Glaeser, and Bruce Sacerdote 2005), and from more traditional family values in Continental European countries and Mediterranean countries (Algan and Cahuc 2005). Blanchard and Thomas Philippon (2006) follow a route closer to ours by arguing that labor market performance is influenced by the quality of labor relations, which is deeply ingrained in cultural features. 
attitudes. Moreover, we show that civic attitudes are shaped, to a large extent, by country-specific effects rather than individual characteristics.

We then provide evidence of cross-country correlations between national civic attitudes and the design of insurance institutions. Countries displaying high civic values tend to insure their workers through unemployment benefits instead of using stringent employment protection. Such a relationship is robust to the inclusion of country fixed effects which account for time invariant national features and which could affect the design of unemployment insurance and employment protection. This finding is consistent with the sharp, opposing pattern between the flexicurity model in Nordic countries such as Denmark, which combines very generous unemployment benefits with low job protection, and Continental European and Mediterranean countries, which mainly insure households against labor market risks through employment protection legislation.

Naturally, the correlation between civic attitudes and the design of labor market institutions does not mean that there is a causal relationship that goes from social attitudes to the unemployment benefits/employment protection trade-off. There is a concern for potential reverse causality since labor market institutions are likely to affect civic attitudes. For instance, the administrative inefficiencies in the provision of unemployment insurance could influence the guilty feelings about cheating on unemployment benefits.

To deal with this reverse causality issue, we estimate the inherited part of civic attitudes that are not instantaneously influenced by the economic and institutional environment of the country in which people are living. We follow an epidemiological approach (see Fernández 2007) by estimating the civic attitudes inherited by the American-born from their ancestors country of origin using the General Social Survey database for the period 1977-2002. We show that the civic attitudes of people who were born and are living in the United States are strongly influenced by the country of origin of their ancestors. This result is consistent with the earlier findings on the transmission of civic culture and democracy from Europe to America (Tom W. Rice and Jan Feldman 1997). We then use this inherited part of civic attitudes by country of origin as an instrument for civic attitudes in the home country ${ }_{5}^{5}$ This strategy enables us to conclude that there is a significant impact of civic attitudes on unemployment benefits and on employment protection in OECD countries during the period of 1980-2003.

\section{The Model}

This model shows how moral hazard caused by uncivic attitudes could influence the implementation of efficient labor market institutions. If it is difficult to provide unemployement insurance because of moral hazard, the incidence of unemployment can be decreased by using employment protection but at some efficiency cost.

\footnotetext{
${ }^{5}$ See Algan and Cahuc (2007) for a similar strategy used to uncover the causal effect of social attitudes on economic development since World War II.
} 
We consider an economy in which a numeraire good is produced with labor. There is a continuum of workers for which the size is normalized to one. Workers can be either employed or unemployed. Employed workers get a wage $w$. Unemployed workers get unemployment benefits $b$ provided by the government. At the beginning of the period, all workers are unemployed. Each worker can then decide to search for a job or not. The job search effort is not verifiable.

Preferences over consumption and job search effort are represented by the utility function $v(c)-\ell e-(1-\ell) \gamma$, where $c \geq 0$ stands for consumption, and $v$ is an increasing, concave, and twice derivable function. The variable $\ell$ is an indicator equal to one if the individual provides a search effort which costs $e>0$ and is equal to zero otherwise. Preferences are influenced by social norms. More precisely, the utility of unemployed workers who get unemployment benefits $b$ is equal to $v(b)-e$ if they provide search effort $(\ell=1)$ and to $v(b)-\gamma, \gamma \geq 0$ if they do not look for a job $(\ell=0)$. The parameter $\gamma$ stands for the utility loss induced by an individuals' feeling of guilt for cheating on unemployment benefits ${ }^{6}$ In the following, we focus on the consequences of such guilt feelings on the design of unemployment insurance and job protection?

There is potentially a large number of firms that can create jobs. Creating a job entails fixed costs denoted by $k>0$. A job produces $x$ units of the numeraire good, where $x \in \mathbb{R}$ is an idiosyncratic shock drawn in a distribution with a continuous, differentiable, cumulative distribution function denoted by $G$. The productivity shock, $x$, which is private information held by the firm, is not contractible. Firms enter into competition to offer wages to workers before the realization of the idiosyncratic shocks that are known only after workers have been hired. Once the shocks are realized, employers may want to fire workers. It costs $f$ to fire a worker ${ }^{8}$ As workers are assumed to be perfectly mobile, competition between firms entails zero expected profits.

There is a government that provides unemployment benefits financed by payroll taxes, denoted by $\tau$, and by layoff taxes, denoted by $f .9$ We assume that the government maximizes the sum of the expected utility of workers! 10

\footnotetext{
${ }^{6}$ Another potential interpretation for $\gamma$ is that of a social stigma or nonpecuniary psychic costs associated with the condition of unemployment. Our preferred interpretation of $\gamma$ as guilt feelings is grounded in the fact that we have empirical data to measure this coefficient.

${ }^{7}$ Assuming that guilt feelings are proportional to the degree of free riding on social benefits would yield similar results.

${ }^{8}$ The model focuses exclusively on the moral hazard associated with unemployment insurance. Actually, the design of the employment protection legislation may also depend on moral hazard problems within the firm. The moral hazard issue is likely to be much more of a concern for the unemployed, however, since their behavior is, by nature, much more difficult to monitor than that of workers present in the workplace. We shall see the empirical results suggest that our approach is relevant to the extent that we find evidence of a negative impact of civic attitudes on employment protection. Moreover, we focus on the moral hazard raised by unemployment benefits due to data limitation. International social surveys mainly document attitudes toward public transfers, which are not necessarily systematically related to attitudes about the workplace.

${ }^{9}$ For the sake of simplicity, in the model, the firing cost is interpreted as a layoff tax used to finance unemployment benefits. Usually, employment protection legislation is made of restrictions which force the employer to transfer income to the fired workers. Advanced notice is an example of such restrictions. This dimension of employment protection, which induces the waste of resources, is not accounted for in our model. Our analysis goes through as long as employment protection is not a pure waste that yields no benefits to employees.

${ }^{10}$ It is well known that the maximization of the sum of the expected utilities can be the outcome of an election process, if elections are represented by the probabilistic voting model in which there are two candidates who announce their electoral platforms simultaneously and noncooperatively (see Torsten Persson and Tabellini 2000, chapter 3).
} 
The time sequence of events runs as follows:

- The government announces the policy $(\tau, f, b)$.

- Workers choose their level of search effort. At the beginning of the period, all workers are unemployed. Only workers who produce a high level of search effort are matched with firms. The others remain unemployed and get unemployment benefits $b$.

- Employers compete to hire workers.

- The idiosyncratic productivity shocks, $x$, occur and employers decide whether to keep the worker or eliminate the job. Employers pay wages and payroll taxes on every continuing job. The elimination of a job gives rise to the payment of layoff taxes. Employed workers get wage $w$, unemployed workers get unemployment benefits $b$.

This problem can be solved by backward induction. The market equilibrium is solved in the first stage. Then, the optimal policy is determined.

\section{A. Market Equilibrium}

Market equilibrium yields labor contracts that allow workers to achieve the maximum level of expected utility compatible with zero expected profits. Labor contracts only include flat wages since the productivity parameter $x$ is private information of the firm, which is not contractible. Moreover, it is assumed that firms cannot commit ex ante to a reservation value of productivity by keeping aside funds payable to a third party in case of layoff (see the discussion in Blanchard and Tirole 2004). Accordingly, at step 4, firms destroy jobs if and only if their profits, $x-w-\tau$, are lower than their destruction costs, $f$. The job destruction decision boils down to the choice of a reservation value for the productivity parameter $x$, denoted by $X$, below which jobs are destroyed. The reservation productivity reads

$$
X=w+\tau-f .
$$

The job destruction rate is equal to $G(X)$. Given the expression $X$ of the reservation productivity, there is a single value ${ }^{11}$ of the wage compatible with the zero profit condition:

$$
\int_{X}^{+\infty}(x-w-\tau) d G(x)-G(X) f=k .
$$

\footnotetext{
${ }^{11}$ As the expected profit decreases with respect to $w$, there is a single, positive equilibrium value for the wage if and only if the two following conditions are fulfilled:

$$
\begin{gathered}
\int_{\tau-f}^{+\infty}(x-\tau) d G(x)-G(\tau-f) f-k>0, \\
\lim \int_{w+\tau-f}^{+\infty}(x-w-\tau) d G(x)-G(w+\tau-f) f-k<0 .
\end{gathered}
$$
}

These conditions are assumed to be fulfilled. 
Equations (1) and (2) define, together with the balanced budget constraint of the government,

$$
\tau[1-G(X)]+(f-b) G(X)=0
$$

the market equilibrium value of the wage $w$ and the reservation productivity $X$ for the set of feasible policies $(\tau, f, b)$. Let us now analyze the choice of the unemployment benefits, payroll taxes, and layoff taxes.

\section{B. Optimal Policy}

The optimal policy maximizes the expected utilities of workers

$$
[1-G(X)] v(w)+G(X) v(b)-e,
$$

subject to three constraints: 12

- The incentive compatibility constraint

$$
[1-G(X)] v(w)+G(X) v(b)-e \geq v(b)-\gamma
$$

- The government balanced budget constraint (3),

- The zero profit condition (2).

It is useful to rewrite this program as the maximization of the sum of expected utilities with respect to $(w, X, b)$ subject to the incentive compatibility constraint (4) and to the equation

$$
\int_{X}^{+\infty}(x-w) d G(x)-G(X) b=k
$$

that is obtained by summing up the balanced budget constraint of the government (3) and the zero profit condition (2). Then, once the optimal value of $(w, X, b)$ is determined, it is possible to use equations (1) and (2) to find out the optimal value of $(\tau, f, b)$.

The computation of the optimal value of $(w, X, b)$, presented in Appendix $\mathrm{B}$, leads to the first result:

RESULT 1: Full insurance, with $w=b$, can be obtained only if the utility loss induced by guilt feelings is sufficiently large.

When the utility cost of cheating on unemployment benefits is high, the incentive compatibility condition (4) is not binding, and the government can provide full

\footnotetext{
${ }^{12}$ We apply the revelation principle so that everyone looks for a job in equilibrium.
} 
insurance. It also turns out that the reservation productivity amounts to zero $(X=0)$ when individuals are perfectly insured. Otherwise, the optimal value of $(w, X, b)$ is defined by equation (5) and by

$$
\begin{aligned}
& X=w-b-\frac{v(w)-v(b)}{v^{\prime}(w)}, \\
& v(w)-v(b)=\frac{e-\gamma}{1-G(X)}>0 .
\end{aligned}
$$

Equation (7) is merely the binding incentive compatibility condition, that shows that the wage is larger than the unemployment benefits if utility losses associated with guilt feelings are small enough. ${ }^{13}$ Equation (6) shows that the government decides to keep jobs filled up to the point where the utility cost (in numeraire good units) of job destruction, $(v(w)-v(b)) /\left(v^{\prime}(w)\right)$, is equal to the gains of job destruction, ${ }^{14} w-b-x$. These two equations lead to the following result (see the proofs in Appendix B):

RESULT 2: Unemployment benefits and the reservation productivity increase with respect to guilt feelings.

Result 2 can be understood as follows. First, when guilt feelings are lower, unemployment benefits are decreased to insure that workers devote sufficient effort to the job search. Furthermore, when guilt feelings decrease, since $v(w)-v(b)=$ $(e-\gamma) /(1-G(X))$, the utility cost of job destruction increases and the optimal reservation productivity drops.

The scheme $(\tau, f, b)$ that allows the government to implement the optimal value of $(w, X, b)$ is defined by equation (6), by the definition of the reservation productivity (1), and by the zero profit condition (2) which reads, using (1),

$$
f=\int_{X}^{+\infty}(x-X) d G(x)-k
$$

This last expression of the zero profit condition implies that layoff taxes decrease with the reservation productivity. This expression, along with Result 2, leads to Result 3.

RESULT 3: Layoff taxes decrease with respect to guilt feelings.

\footnotetext{
${ }^{13}$ A more rigourous presentation is provided in Appendix B.

${ }^{14}$ Note that $X$ in equation (6) is negative when the incentive compatibility constraint is binding. The reason is that there is zero utility of leisure. If the utility of unemployed workers is $v(\mu+b)$, where $\mu \geq 0$ stands for the utility of leisure rather than $v(b)$, then $X$ can be positive (although less than $\mu$ ).
} 
The interpretation of this result is straightforward. When guilt feelings are stronger, the government can provide higher unemployment benefits. Since workers are better insured when they lose their job, it is optimal to destroy more jobs. This situation can be achieved with lower layoff taxes.

The next section provides empirical tests of the main predictions of the theoretical model, in which better civic attitudes toward government benefits lead to lower job protection and higher unemployment benefits.

\section{Empirical Results}

In this section, we estimate to what extent cross-country differences in civic attitudes could explain the observed heterogeneity in the design of public insurance policies on the labor markets. First, we document that people living in different OECD countries do differ significantly in their civic attitudes toward government benefits, these differences being mainly explained by country-specific features. We then provide evidence of cross-country correlations between unemployment benefits (UB), employment protection (EP), and national civic values that are in line with the predictions of our theoretical framework. Finally, we present our instrumental variable approach in order to deal with reverse causality issues.

\section{B. Cross-country Differences in Civic Attitudes}

Data on Civic Attitudes.-Evidence of cross-country differences in civic attitudes are based on the World Values Survey (WVS) database, which provides questions on civic attitudes for an extensive set of countries including OECD, Eastern European, and Latin American countries. The WVS database is made up of three main waves: 1981-1984, 1990-1993, and 1999-2003, denoted henceforth as 1980, 1990, and 200015 The coverage depends on the wave, starting with 22 countries in the 1980 wave, and ending with around 80 countries in the last wave.

The WVS database provides a specific question on civic attitudes directly related to our model. The question reads as follow: "Do you think it can always be justified, never be justified or something in between to claim government/state benefits to which you have no rights?" The answers are given on an ordered scale from 1 for "Never justifiable" to 10 for "Always justifiable." To ease the interpretation of the results, we group the answer categories together to represent individuals with strong civic attitudes. We create a dummy variable which takes on the value one if the respondent answered "Never justifiable" in the WVS, and zero otherwise. As a robustness check, we also run the regressions on the original variable ranked between 1 and 10, and test different mappings from the ordered 1-10 variable into a 1-0 dummy ${ }^{16}$ The question on civic attitudes with respect to government benefits is certainly the most relevant one for investigating the link between civicmindedness

\footnotetext{
${ }^{15}$ The WVS also provides a wave in 1995 but for a smaller set of countries and questions.

${ }^{16}$ Note that only the two extreme answers, one and ten, are labeled in the questionnaire and thus have a clear meaning for the respondent. This is why our preferred mapping groups together the answers "Never justifiable" on one side and all other answers on the other side.
} 
and public insurance policies. This question directly measures the extent of moral hazard, identified as a guilty feeling in the model, which could undermine the provision of efficient unemployment insurance. ${ }^{17}$

Yet, the extent to which this moral issue could matter in explaining the willingness of people to support public insurance policies is also likely to depend on whether they believe in the trustworthiness of others. We measure this dimension by using the following question on trust: "Generally speaking, would you say that most people can be trusted or that you need to be very careful in dealing with people?" The answer is given on a 1-0 scale, the variable being equal to one if the respondent believes in the trustworthiness of others and zero otherwise.

Our analysis includes the main OECD countries: Australia, Austria, Belgium, Canada, Denmark, France, Germany, Ireland, Italy, Japan, Mexico, the Netherlands, New Zealand, Norway, Portugal, Spain, Sweden, Switzerland, the United Kingdom and the United States. We also include formerly planned economies: Hungary, the Czech Republic, and Poland. To some extent these countries provide a useful, natural experiment since they have implemented different labor market institutions following a common shock caused by the fall of communism. By grouping the different countries and different waves together, this selection leaves us with 76,221 working-age individuals in the WVS database. The number of observations by country reaches at least 1,107 individuals in the WVS database (see Appendix D for summary statistics).

Cross-country Differences. - We start with simple cross-country evidence on the average level of civic attitudes. Figure 1 reports the basic mean reply to our main question concerning government benefits by averaging the three waves of the WVS database. This figure already highlights important facts. First, a much larger share of individuals in Nordic countries display strong civic attitudes. Denmark is a clear outlier with 88 percent of households strongly blaming cheating on government benefits. Such a civic stand is shared by almost 80 percent of individuals in other Nordic countries such as Norway, Sweden, and the Netherlands. Second, European countries lag far behind their Nordic counterparts. On average, no more than 65 percent of individuals in Continental European and Mediterranean countries blame uncivil behavior. Third, the former planned economies in Eastern Europe and Latin America resemble Continental and Mediterranean European countries. The only outlier is Hungary, which is much closer to Nordic countries on this issue. We will see later that it is the only Eastern European country to have implemented generous unemployment insurance. Fourth, the Anglo-Saxon countries stand in an intermediate position, between Nordic countries and the others, with more than 70 percent of households blaming uncivic attitudes. It is also shown in Appendix D that the

\footnotetext{
${ }^{17}$ The WVS questions about cheating on government benefits could also reflect more general beliefs about the sources of an individuals misfortunes. Individuals who think that society is responsible for one becoming unemployed (rather than the lack of one's own effort) could be less reluctant to cheat on unemployment benefit. This channel can be measured by the WVS question: "Why, in your opinion, are there people who live in need? Because of laziness and lack of willpower or because society treats them unfairly?" Yet, the answer to this question turns out to be only weakly, positively correlated with the answers concerning cheating on government benefits, with a correlation of 0.087 over the three waves of the WVS database.
} 


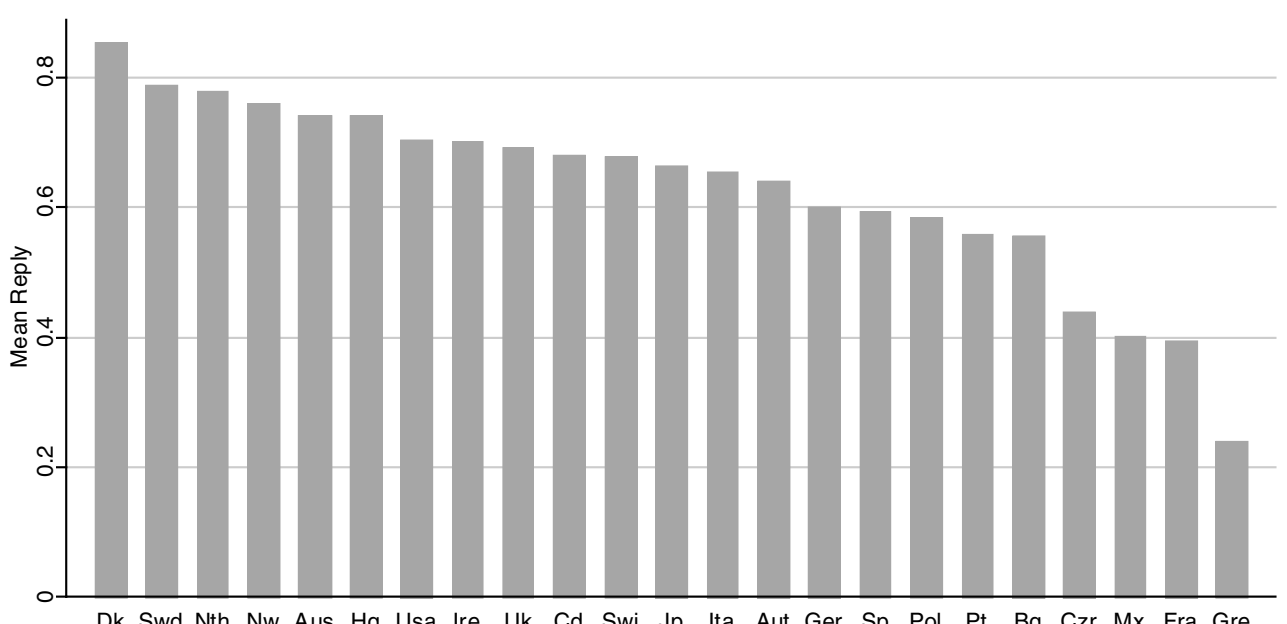

FIGURE 1

Notes: Mean reply to the question: "Do you think it can always be justified, never be justified or something in between to claim government/state benefits to which you have no rights." The score associated with the answer "never" is one. The score of other answers is zero.

Source: WVS 1980, 1990, 2000.

ordering of countries with regard to civic attitudes has remained stable between the waves 1980 and 2000.

We now look more closely at the national components of civic attitudes. We run a series of regressions of the following form:

$$
a_{i t}=\alpha+\mathbb{F}_{c}+\gamma \boldsymbol{X}_{i t}+\mathbb{F}_{t}+\varepsilon_{i t},
$$

where $a_{i t}$ represents civic attitudes of individual $i$ at date $t . \boldsymbol{X}_{i t}$ is our control for individual characteristics such as age, sex, education, income category, employment status, religious affiliation, and political orientation. $\mathbb{F}_{t}$ is a time dummy variable. $\varepsilon_{i t}$ is a random error term at date $t$.

The national component of civic attitudes is captured by country fixed effects $\mathbb{F}_{c}$, representing dummy variables for the country $c$, where the individual $i$ is observed at date $t$. Denmark, which displays the highest average level of civic attitude, is used as the reference group. To disentangle the country-specific effect, we also control for the main individual characteristics such as gender, age and age squared, years of education, employment status, income category, political orientation, and religious affiliation. This estimation is run on the three main waves of the WVS $(1980,1990$, 2000).

Table 1 reports the probit estimates of the civic variable. The dependent variable takes the value one if the respondent thinks that cheating on government benefits is never justifiable and zero otherwise. All the standard errors are corrected for clustering at the country level. Table 1 shows that all country dummies are significant at the 1 percent level. And the adjusted $R$-squared is almost three times as high with 
Table 1-Probit Estimation of Civic Attitudes

\begin{tabular}{|c|c|c|}
\hline \multirow[b]{2}{*}{ Dependent variable } & \multicolumn{2}{|c|}{$\begin{array}{l}\text { Cheat on government benefits: } \\
\text { Never justifiable }=1\end{array}$} \\
\hline & Coeff. & Std. error \\
\hline Country dummies & \multicolumn{2}{|c|}{ Yes*** } \\
\hline Male & $-0.067 * * *$ & $(0.011)$ \\
\hline Age & $0.033 * * *$ & $(0.001)$ \\
\hline Age2 & $-0.000 * * *$ & $(0.000)$ \\
\hline Education & $0.035^{* * *}$ & $(0.002)$ \\
\hline Unemployed & \multicolumn{2}{|c|}{ Reference } \\
\hline Employed & $0.165 * * *$ & $(0.025)$ \\
\hline Inactive & $0.102 * * *$ & $(0.027)$ \\
\hline Income_class: middle & \multicolumn{2}{|c|}{ Reference } \\
\hline Low_class & -0.181 *** & $(0.013)$ \\
\hline High_class & $0.044 * * *$ & $(0.015)$ \\
\hline \multicolumn{3}{|l|}{ Political orientation: } \\
\hline Center & \multicolumn{2}{|c|}{ Reference } \\
\hline Left & $-0.047 * * *$ & $(0.014)$ \\
\hline Right & $0.090^{* * *}$ & $(0.014)$ \\
\hline \multicolumn{3}{|l|}{ Religious affiliation: } \\
\hline No_religion & \multicolumn{2}{|c|}{ Reference } \\
\hline Catholic & 0.010 & $(0.583)$ \\
\hline Protestant & $0.085^{* * *}$ & $(0.022)$ \\
\hline Buddhist & -0.001 & $(0.050)$ \\
\hline Muslim & -0.106 & $(0.114)$ \\
\hline Jewish & 0.000 & $(0.992)$ \\
\hline Other_religion & 0.034 & $(0.029)$ \\
\hline Time dummies & \multicolumn{2}{|c|}{ Yes*** } \\
\hline Pseudo- $R^{2}$ & \multirow{2}{*}{\multicolumn{2}{|c|}{$\begin{array}{c}0.098 \\
60.014\end{array}$}} \\
\hline Observations & & \\
\hline
\end{tabular}

Notes: WVS database 1980, 1990, 2000. Standard errors corrected for clustering at the country level:

*** Significant at the 1 percent level.

** Significant at the 5 percent level.

* Significant at the 10 percent level.

country fixed effects than the one generated by the specification without country fixed effects. 18

The marginal coefficients of each country are reported in Figure 2. They indicate to what extent living in countries other than Denmark lowers the probability of displaying good civic attitudes. The coefficients go from 0 for the reference group (Denmark) to -0.58 for individuals living in Greece, which displays the lowest level of civic attitudes. Latin American and Mediterranean countries display, in general, the highest gap in civic culture with Denmark. Compared to Denmark, the probability of having good civic attitudes is 54 percent lower in Mexico, 32 percent lower in Spain, 29 percent lower in Portugal, and 25 percent lower in Italy. Another distinctive group consists of Eastern European countries in which the probability of sharing high civic stands is 35 percent lower in Slovakia and 33 percent lower in Poland. Hungary is an outlier which displays civic attitudes more comparable to those of

\footnotetext{
${ }^{18}$ The specifications without country fixed effects yields an $R^{2}=0.036$. We have also checked for different specifications with country-specific trends and interactions between country fixed effects and individual characteristics. Similarly, we have also run the same regressions by including, as demographic controls, only exogenous variables (age and gender) and excluding potential endogenous characteristics such as employment status. The results across these different specifications were fairly similar.
} 


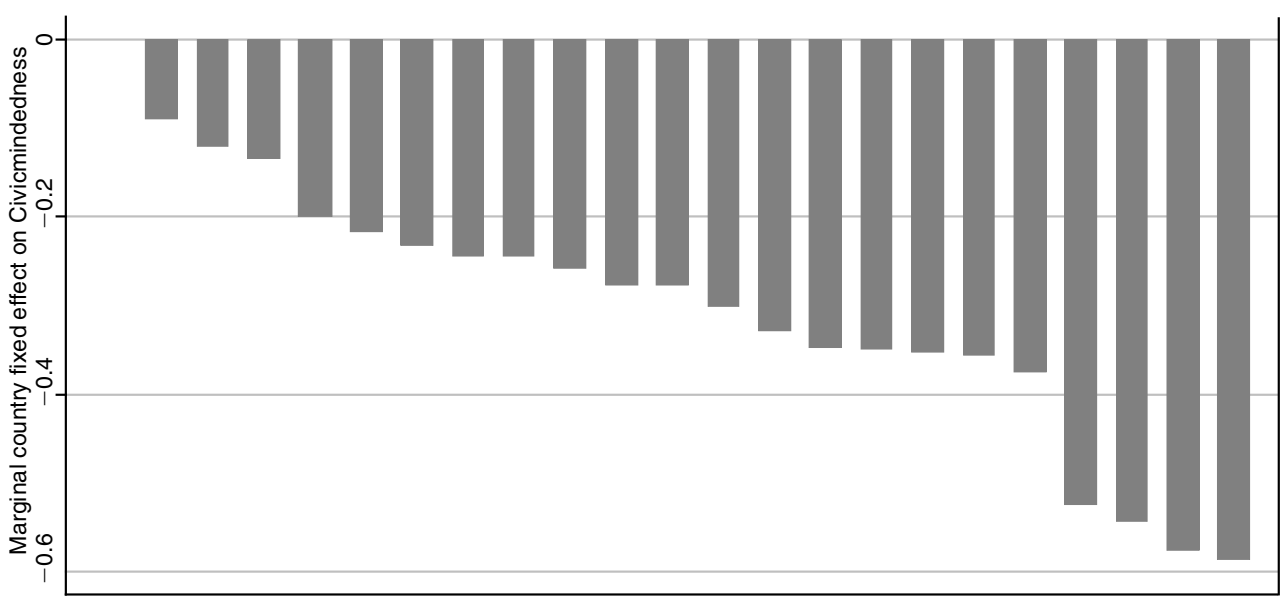

Dk Nth Swd Aus Nw Uk Usa Ire Hg Cd Ita Aut Ger Jp Pol Pt Swi Sp Bg Czr Fra Mx Gre

FIGURE 2

Notes: Marginal country effects associated with the question: "Do you think it can always be justified, never be justified, or something in between to claim government/state benefits to which you have no rights." The score associated with the answer "never" is one. The score of other answers is zero.

Source: WVS 1980, 1990, 2000.

Continental European countries. The group of countries much closer to Denmark is made up of Nordic and Anglo-Saxon countries. Civic attitudes in Norway and Australia are only 6 percent and 12 percent lower than in Denmark.

Table 1 also reports the role of individual characteristics. The probability of considering it unjustifiable to cheat on government benefits increases with the level of education, age, and employment status (whether one is employed or unemployed). Being Protestant or belonging to the right wing is also associated with better civic attitudes. But, it turns out that the coefficients of individual controls are much smaller than those associated with the country dummies. In terms of marginal effect $\frac{19}{19}$ the probability of thinking that cheating on government benefits is never justifiable increases by 3 percent if the respondent is Protestant rather than a nonreligious person and by 1 percent by year of education.

We also perform several robustness checks. Since our mapping of the originally scaled 1-10 civic variable into a 1-0 dummy is arbitrary, we rerun ordered probit estimates on the original 1-10 civic variable. We found little change in the ordering of countries. In particular, the correlation between the country fixed effects estimated with these two different specifications is almost perfect, with the $R^{2}$ reaching $0 . 9 4 \longdiv { 2 0 }$

We end this section by looking at the cross-country heterogeneity in the trust variable. As discussed above, this variable measures the beliefs of individuals about

\footnotetext{
${ }^{19}$ The coefficients reported in the tables correspond to the probit estimates. We use the corresponding marginal coefficients when interpreting the size effects in the text.

${ }^{20} \mathrm{We}$ also tried different mapping of the original $1-10$ variable into a $1-0$ dummy variable by grouping together the first two or the first three answers, but without any noticeable change. The tables of results are available upon request.
} 
the trustworthiness of others. It could thus be an important determinant of the political support for generous unemployment benefits. We estimate the marginal country fixed effect on the probability that the respondent answers yes to the question: "Generally speaking, would you say that most people can be trusted or that you need to be very careful in dealing with people?" We run this regression on the three WVS waves and control for the same set of individual characteristics as we did for the civic variable. The marginal country fixed effects are reported in Appendix D. The ordering of countries with respect to the trust variable and the civic variable are similar. Nordic countries are very trusting countries, while Mediterranean and, to a lesser extent, Continental European countries display a very low level of trust in each other. The Anglo-Saxon countries fall in the middle. As it happens, the correlation between national components of civicmindedness and trust is fairly high, the coefficient of correlation being equal to 0.66 , and the $R^{2}$ reaching 0.54 . These two indicators provide complementary information on the extent of civic attitudes in each country.

\section{B. Correlation Between Civic Attitudes and Labor Market Institutions}

Data on Unemployment Insurance and Employment Protection.-We use different indicators to measure the extent of the generosity of unemployment benefits. The first indicator consists of public expenditure per unemployed person, as a percentage of GDP per capita. This indicator is given by the OECD social expenditure database during the period 1980-2003. This database reports the total public expenditure on unemployment benefits. We then calculate public expenditure per unemployed worker by dividing this indicator by the yearly number of unemployed people in each country, and divide the amount by the GDP per capita.

This first indicator has the advantage of combining information on both the level and length of unemployment benefits. This measure is more comprehensive than traditional indicators of replacement rate and benefit duration taken separately. However, a potential concern with this indicator is that it could be endogenous with respect to the composition of unemployment. For instance, this indicator might be high in a country which has a high proportion of long-term unemployed and highbenefit duration.

We check the robustness of the results by constructing a composite index based on the replacement rate and the length of benefits. The replacement rate (RR) is taken from the OECD database on unemployment insurance. The benefit duration index (BD) is provided by the indicator of Stephen Nickell et al. (2001), which accounts for decreasing replacement rate by duration. The benefit duration indicator is a weighted average of the ratio of the replacement rate received during the first year of unemployment over the replacement rate received during the second and third year, and the ratio of the first year replacement rate over the replacement rate received the fourth and fifth years. If benefit provision is constant over the unemployment years, the indicator is equal to one. We then use the indicators of benefit duration and replacement rate to construct a composite index equal to the average of these two indicators. We also check the robustness of the results by looking at the replacement rate and the benefit duration taken separately. 


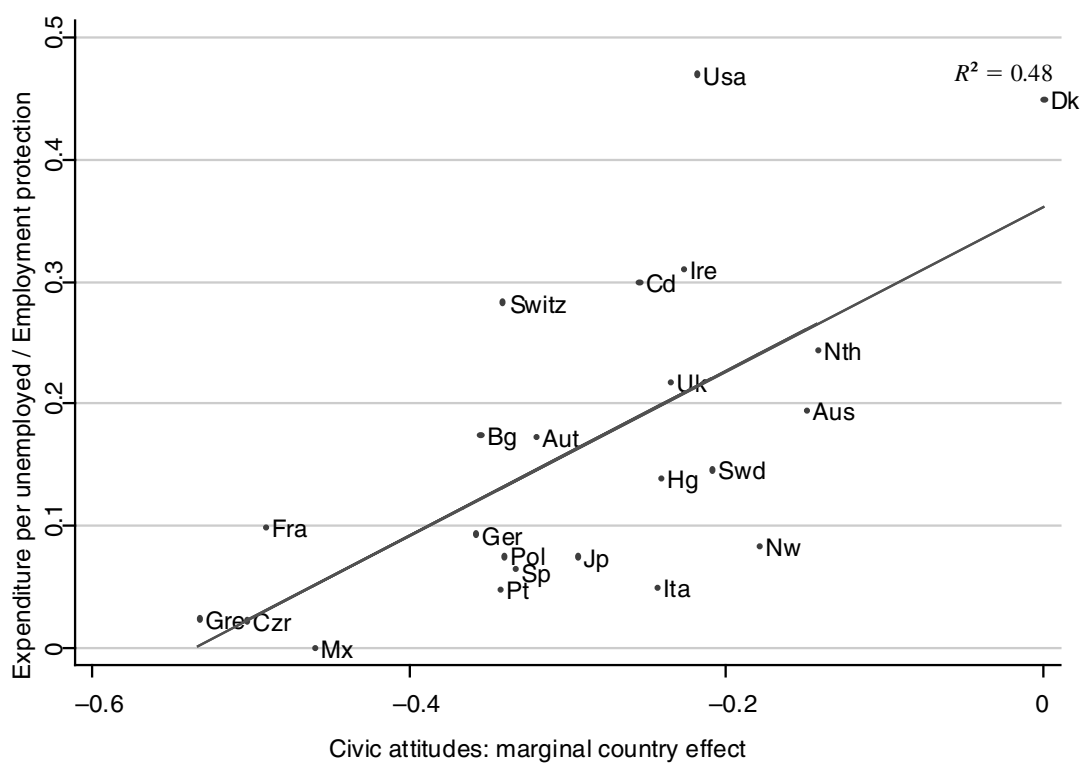

FIGURE 3

Notes: Correlation between civic attitudes and the ratio of public expenditure per unemployed over the indicator of employment protection. Civic attitudes are measured by the estimated marginal country fixed effects in the probit regression of the question "Do you think it is unjustifiable to cheat on government benefits."

Source: OECD and WVS database 1980-2000.

The measure of employment protection draws upon the OECD indicator of the stringency of job protection over temporary and regular contract. This employment protection indicator combines both the procedural difficulty to lay off workers and the level of layoff taxes. The OECD indicator then adds up the country scores along these different dimensions of employment protection. It can take values between zero and six. In our database, the indicator takes on values ranging from 0.2 to 4.1 , the higher the level of this index, the more stringent the employment protection becomes.

To illustrate the cross-country heterogeneity in the trade-off between unemployment benefits and employment protection, Figure 3 presents a simple correlation between the ratio UB/EP and civic attitudes. Public expenditure per unemployed and the OECD employment protection index are averaged for the period 1980-2003, consistently with the time span of the WVS database. The marginal country fixed effects on civic attitudes are derived from the pooled probit estimation over the three waves (1980, 1990, and 2000). Figure 3 shows a steady, positive correlation between civic attitudes and the UB/EP ratio. Nordic countries, which display higher civic attitudes, tend to insure their workers through unemployment benefits instead of employment protection. In contrast, countries with lower civic attitudes are more prone to protect jobs rather than unemployment spells. Anglo-Saxon countries also fit into this picture well. Even if public policies, taken as a whole, play a lesser role in an Anglo-saxon country like the United States, the latter tends to insure the workers more through unemployment benefits than layoff taxes. This result is consistent with 
the fact that civic attitudes are more developed in the Anglo-Saxon countries relative to Mediterranean and Continental European countries. In Appendix E, we report separate evidence on the cross-country heterogeneity in UB and EP, respectively, and the correlation at stake with national civic attitudes.

Correlation Between Labor Market Institutions and Civic Attitudes.-This section provides simple evidence on cross-country correlations between civic attitudes and UB and EP institutions by running the following type of regressions:

$$
I_{c t}=\eta_{0}+\eta_{1} \mathbb{F}_{c, t}+\eta_{2} E\left(X_{i t} \mid c\right)+\varepsilon_{c t},
$$

where $I_{c t}$ denotes UB or EP at date $t$ in country $c . \mathbb{F}_{c, t}$ stands for the country average of civic attitudes at date $t$, conditional on the individual characteristics of individual $i$ such as age, number of years of education, employment status, and religious affiliation. These national features of civic attitudes are captured by the country fixed effects estimated in the previous section, but for each period $t . E\left(\boldsymbol{X}_{i t} \mid c\right)$ denotes a vector of the average characteristics of the population and other potential aggregate factors.

We run generalized least square regressions of the different insurance institutions on the country fixed effects capturing national civic attitudes controlling for heteroskedacity. To get the maximum amount of observations for this cross-country comparison, we run separate probit estimates on the civic variable for the three waves (1980, 1990, and 2000). Public policies are measured by averaging the indicators for unemployment generosity and employment protection in the early 1980s (1980-1984), the early 1990s (1990-1994) and the early 2000s (2000-2003). The panel of observations is not balanced since some countries are missing during the 1980 wave of the WVS database. In addition, the number of observations drops when we use the replacement rate and the benefit duration indicators since they are not documented for all Eastern European and Latin American countries.

We also include additional variables for $E\left(\boldsymbol{X}_{i t} \mid c\right)$ which could drive the relationship between labor market institutions and civic attitudes. Labor market institutions and civic attitudes could be linked to national income ( $g d p k$ ), proxied by the GDP per capita in 1995 US dollars (billion). We also include the degree of openness of the country (openness), which could give rise to more uncertainty for households and could have fueled their need for more insurance (Jonas Agell 2001). This variable measures the share of imports and exports as a percentage of GDP and is given by the Penn World Table. The data are taken as averages for the period 1980-1984, 1990-1994, and 2000-2003. All regressions control for time period dummies.

Table 2, row I reports the regression of UB and EP indicators on civic attitudes, measured by the marginal country fixed effects in the probit regression of the 1-0 civic variable. A positive and statistically significant relationship at the 1 percent level shows up between this measure of civic values and the generosity of unemployment benefits no matter what index is used to measure unemployment benefits. Columns 1 through 4 show that this statistically significant relationship holds for the public expenditures per unemployed, the replacement rate index (RR), the benefit duration index (BD), and the weighted average of benefit duration and replacement 
Table 2-Civic Attitudes and Labor Market Institutions: GLS Estimates 1980-2003

\begin{tabular}{|c|c|c|c|c|c|}
\hline & \multicolumn{4}{|c|}{ Unemployment benefits (UB) } & \multirow{2}{*}{$\begin{array}{c}\begin{array}{c}\text { Employmen } \\
\text { protection }\end{array} \\
\text { EP } \\
(5)\end{array}$} \\
\hline & $\begin{array}{l}\text { Expenditure per } \\
\text { unemployed } \\
(1)\end{array}$ & $\begin{array}{l}\text { Replacement } \\
\text { rate } \\
(2)\end{array}$ & $\begin{array}{l}\text { Benefit } \\
\text { duration } \\
(3)\end{array}$ & $\begin{array}{c}\mathrm{RR}-\mathrm{BD} \\
(4)\end{array}$ & \\
\hline $\begin{array}{l}\text { Civic attitudes }(1-0) \\
\quad \text { (I) } \\
N\end{array}$ & $\begin{array}{l}0.397 * * * \\
(0.105) \\
57\end{array}$ & $\begin{array}{l}0.588 * * * \\
(0.060) \\
48\end{array}$ & $\begin{array}{l}0.329 * * * \\
(0.081) \\
48\end{array}$ & $\begin{array}{l}0.424 * * * \\
(0.063) \\
48\end{array}$ & $\begin{array}{c}-2.849 * * * \\
(0.501) \\
57\end{array}$ \\
\hline $\begin{array}{l}\text { Civic attitudes (1-10) } \\
\quad \text { (II) } \\
\quad N\end{array}$ & $\begin{array}{l}0.106 * * * \\
(0.034) \\
57\end{array}$ & $\begin{array}{l}0.170 * * * \\
(0.033) \\
48\end{array}$ & $\begin{array}{c}0.115^{* * *} \\
(0.032) \\
48\end{array}$ & $\begin{array}{l}0.140 * * * \\
(0.020) \\
48\end{array}$ & $\begin{array}{c}-0.930 * * * \\
(0.143) \\
57\end{array}$ \\
\hline $\begin{array}{l}\text { Trust }(1-0) \\
\quad(\text { III }) \\
\quad N\end{array}$ & $\begin{array}{l}0.478 * * * \\
(0.111) \\
54\end{array}$ & $\begin{array}{l}0.771 * * * \\
(0.073) \\
47\end{array}$ & $\begin{array}{c}0.147 \\
(0.112) \\
47\end{array}$ & $\begin{array}{l}0.369 * * * \\
(0.081) \\
47\end{array}$ & $\begin{array}{c}-2.733 * * * \\
(0.757) \\
55\end{array}$ \\
\hline
\end{tabular}

Note: Additional controls: GDP per capita, openness, and time dummies.

Table 3-Civic Attitudes and the UB/EP Trade-OFF: GLS Estimates 1980-2003

\begin{tabular}{lcc}
\hline \hline & UB/EP & UB/EP \\
& Public expenditure per unemployed/EP & Composite index RR-BD/EP \\
\hline Civic attitudes (1-0) & $0.378^{* * * *}$ & $0.620^{* * * *}$ \\
$(\mathrm{I})$ & $(0.044)$ & $(0.193)$ \\
$N$ & 56 & 48 \\
Civic attitudes (1-10) & $0.108^{* * *}$ & $0.200^{* * *}$ \\
(II) & $(0.014)$ & $(0.063)$ \\
$N$ & 55 & 48 \\
Trust (1-0) & $0.556^{* * *}$ & $0.720^{* *}$ \\
(III) & $(0.081)$ & $(0.244)$ \\
$N$ & 54 & 47 \\
\hline
\end{tabular}

Note: Additional controls: GDP per capita, openness, and time dummies.

rate, respectively. The same result holds when we restrict the comparison to exactly the same sample of countries for each indicator. The coefficients are economically sizeable. Column 1 indicates that a 1 percent increase in the probability of saying it is never justifiable to cheat on government benefits would be associated with a rise of 0.39 percent in expenditure per unemployed and an increase of 0.58 percent in the replacement rate.

Table 2, column 5 shows that the stringency of employment protection legislation is correlated negatively with country civic values. The negative relationship is statistically significant at the 1 percent level and economically sizeable. To get a sense of the economic magnitude of the OLS coefficient, we rescale the EP indicator between $0-1$ so that it amounts to zero in the country displaying the lowest employment protection legislation, while the indicator is equal to one in the country with the most stringent legislation. With this rescaling, it turns out that a 1 percent increase in civic values would be associated with a 0.7 percent decrease in employment protection legislation.

Table 3, row I presents the regression of the ratio UB/EP on country civic attitudes. The measure for UB is given by public expenditure per unemployed in column 1 and 
by the composite index of replacement rate and benefit duration in column 2. In both cases, the ratio of UB over EP is correlated positively with country civic attitudes. The coefficients are statistically significant at the 1 percent level for both measures of public expenditure per unemployed and the composite index of replacement rate and benefit duration. The effects are also economically sizeable. A 1 percent increase in civic attitudes would lead to a 0.37 percent increase in the UB/EP ratio.

We check the robustness of this correlation pattern by looking at different indicators for civic attitudes. We first measure country civic attitudes by using the originally coded 1-10 civic variable. In that case, country civic attitudes correspond to the country fixed effects estimated by ordered probit, and thus do not have any direct economic interpretation. But row II in Tables 2 and 3 shows that the same statistically significant correlation pattern holds between this measure of civicmindedness and UB and EP institutions. We also test to what extent the UB/EP trade-off can be associated with the cross-country heterogeneity in the level of trust. Country levels of trust are measured by the marginal country fixed effects estimated by probit regression on the trust variable. Row III of Tables 2 and 3 shows that the correlation pattern between insurance policies and the trust variable is similar to that found with the civic variable. And the coefficients are of the same order of magnitude as the ones found with the $1-0$ civic variable.

Time Variation in Civic Attitudes and Labor Market Institutions.-Even if civic attitudes and labor market institutions have experienced little change over the last two decades of the twentieth century, it might be of interest to analyze the correlation between the time variation in civic attitudes and changes in UB and EP. To investigate this dimension, we need to control for country fixed effects in the previous regressions. Moreover, including these country effects allows us to control for other time invariant national features which could affect the design of unemployment insurance and employment protection.

In order to get enough time variation in civic attitudes, we look at attitudes at two different dates that are distant enough. We select only the two waves 1980 and 2000 henceforth. The data for the dependent variables and the other controls are taken as averages for the periods of 1980-1984 and 2000-2003. Moreover, we focus on the indicator of civic attitudes that displays the main variation across this period. For that purpose, we focus on the beliefs in the trustworthiness of others measured by the $1-0$ trust variable. ${ }^{21}$

Figure 4 reports a scatterplot of the changes in the ratio UB over EP on changes in the country level of trust. The $y$-axis reports the difference in the ratio between 2000 and 1980, while the $x$-axis reports the difference in the country level of trust between the two periods. The correlation is positive and highly significant, 78 percent of the variation in the UB-EP ratio being associated with changes in the country level of trust. In all countries, the level of trust has decreased between 1980 and 2000, relative to Denmark. But countries which have experienced the lowest drop, such as the Netherlands and Germany, are also those where the ratio of unemployment benefits

\footnotetext{
${ }^{21}$ The results are statistically less significant when we measure civic attitudes with the $1-0$ civic variable, which displays less time variation than the 1-0 trust variable.
} 


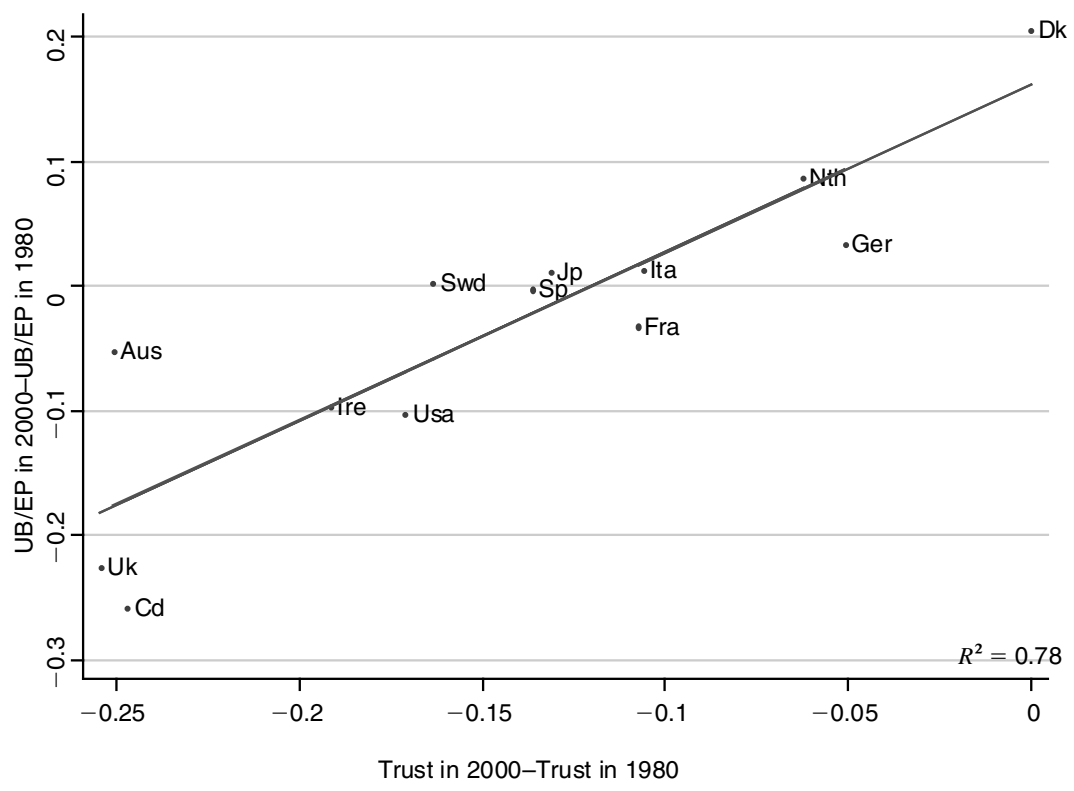

FIGURE 4

Note: Correlation between changes in the ratio of UB over EP and changes in the country level of trust between 2000 and 1980.

Source: WVS and OECD.

Table 4-Time Variation in Civic Attitudes and Labor Market Institutions: OLS Estimates $1980-2003$

\begin{tabular}{|c|c|c|c|c|}
\hline & $\begin{array}{c}\text { Expenditure } \\
\text { per unemployed } \\
(1)\end{array}$ & $\begin{array}{l}\text { EP } \\
(2)\end{array}$ & $\begin{array}{l}\text { Public expend/EP } \\
\text { (3) }\end{array}$ & $\begin{array}{c}\text { RR-BD/EP } \\
\text { (4) }\end{array}$ \\
\hline Trust (1-0) & $\begin{array}{l}0.450 * * \\
(0.194)\end{array}$ & $\begin{array}{r}-4.799 * \\
(2.492)\end{array}$ & $\begin{array}{l}1.355^{* * * *} \\
(0.239)\end{array}$ & $\begin{array}{l}1.673^{* * * *} \\
(0.259)\end{array}$ \\
\hline Country fixed effects & Yes*** & Yes*** & Yes*** & Yes*** \\
\hline Number & 35 & 35 & 35 & 31 \\
\hline
\end{tabular}

Note: Additional controls: GDP per capita, openness, and time dummies.

over employment protection has increased in line with Denmark. In contrast, this ratio has decreased mainly in Anglo-Saxon countries, due to a drop in unemployment benefit generosity, while their country level of trust has experienced the sharpest decline between 1980 and 2000. These results provide tentative evidence that trustworthiness, civicmindedness, and labor market institutions have moved together over the last two decades.

Table 4 reports OLS estimates of the within correlation between civic attitudes and unemployment benefits (UB), employment protection (EP), and the ratio of these two variables (UB/EP). We measure civic attitudes with the country fixed effects associated with the 1-0 trust variable. Column 1 shows that there is a positive correlation between variations in civic attitudes and variations in the generosity 
of unemployment benefits measured by public expenditure per unemployed. The relationship is statistically significant at the 5 percent level.

Table 4, column 2 reports the panel regression of employment protection on civic attitudes. The relationship turns out to be negative and statistically significant. Table 4, column 3 reports the panel regression of the ratio UB over EP on the country levels of civic attitudes, where UB is measured by public expenditure per unemployed. Column 4 reports the same regression when we measure the ratio UB over EP by using the composite index of replacement rate and benefit duration. An increase in trust in others turns out to be associated with a rise in unemployment benefits relative to employment protection. The correlations are statistically significant at the one percent level and are of the same order for the two ratios.

Naturally, at this stage, one should be careful interpreting this evolution as a relation of causality. Variations in social attitudes are likely to be influenced in turn by changes in economic policies.

\section{Instrumental Variable Estimates}

The previous estimates of equation (9) suggest that the correlation between civic attitudes and labor market institutions may reflect an influence of civic attitudes on labor market institutions. Now, we give further evidence on this causal relationship by showing that the inherited civic attitudes are significantly correlated with unemployment benefits and employment protection. By definition, civic attitudes are inherited if they are not determined by the current economic and institutional environment of the country in which people live. In order to evaluate the inherited part of civic attitudes, we estimate the influence of the country of origin on the attitudes of people who were born in and are living in the United States. We then use the inherited part of civic attitudes of Americans coming from different countries of origin as an instrument for civic attitudes of people in the home countries. Note that reverse causality could still be an issue if past labor market institutions affected civic attitudes of people who came to the United States and thus still influence the civic values passed on to their descendants. Yet, this problem might not be an issue here since unemployment insurance and employment protection legislation was reshaped after the 1973 oil crisis in most countries. The features of unemployment benefits and employment protection observed over the last two decades of the twentieth century are thus unlikely to have affected the civic attitudes of the ancestors of the sample of Americans we focus on, since these ancestors were living in countries with very different labor market institutions by that time.

Civic Attitudes in the United States and in the Home Countries.-For consistency with the previous estimations of civic attitudes in the home countries, equation (8), we run the following probit estimates on individual civic attitudes of Americans:

$$
\tilde{a}_{j c t}=\tilde{a}+\tilde{\mathbb{F}}_{c}+\tilde{\gamma} \tilde{\boldsymbol{X}}_{j t}+\tilde{\mathbb{F}}_{t}+\tilde{\varepsilon}_{j c t}
$$

The left-hand-side variable $\tilde{a}_{j c t}$ represents the civic attitudes of American $j$ in period $t$ whose ancestors came from country $c . \tilde{\boldsymbol{X}}_{j t}$ is our measure of individual 
Table 5-Civic Attitudes by Country of Origin and in the Home Country: Probit Estimates

\begin{tabular}{|c|c|c|c|c|c|}
\hline & \multicolumn{5}{|c|}{$\begin{array}{l}\text { Unjustifiable/seriously wrong to cheat on } \\
\text { government benefits }=1\end{array}$} \\
\hline & \multicolumn{2}{|c|}{$\begin{array}{l}\text { Country of origin } \\
\text { GSS } 1991 \text { and } 1998 \\
\text { (1) }\end{array}$} & & \multicolumn{2}{|c|}{$\begin{array}{c}\text { Home country } \\
\text { WVS } 1990 \text { and } 2000 \\
\text { (2) }\end{array}$} \\
\hline & Coeff. & Std. error & & Coeff. & Std. error \\
\hline Age & 0.001 & $(0.002)$ & \multirow{19}{*}{ Reference } & $0.009 * * *$ & $(0.000)$ \\
\hline Men & -0.110 & $(0.064)$ & & $-0.052 * * *$ & $(0.010)$ \\
\hline Education & $0.047 * * *$ & $(0.012)$ & & $0.031^{* * *}$ & $(0.001)$ \\
\hline Austria & $-0.228 * * *$ & $(0.063)$ & & $-0.670 * * *$ & $(0.038)$ \\
\hline Belgium & $-0.679 * * *$ & $(0.046)$ & & $-1.040 * * *$ & $(0.037)$ \\
\hline Canada & $-0.303^{* * *}$ & $(0.033)$ & & $-0.379 * * *$ & $(0.039)$ \\
\hline Denmark & & & & & \\
\hline France & $-0.337 * * *$ & $(0.023)$ & & $-1.065^{* * *}$ & $(0.038)$ \\
\hline Germany & $-0.257 * * *$ & $(0.020)$ & & $-0.819 * * *$ & $(0.035)$ \\
\hline Greece & $-0.578 * * *$ & $(0.034)$ & & $-1.677 * * *$ & $(0.054)$ \\
\hline Hungary & $0.132 * * *$ & $(0.020)$ & & $-0.399 * * *$ & $(0.040)$ \\
\hline Ireland & $-0.300^{* * * *}$ & $(0.018)$ & & $-0.610^{* * *}$ & $(0.039)$ \\
\hline Italy & $-0.373^{* * *}$ & $(0.021)$ & & $-0.649 * * *$ & $(0.037)$ \\
\hline Mexico & $-0.760 * * *$ & $(0.084)$ & & $-1.324 * * *$ & $(0.039)$ \\
\hline Netherlands & $0.053 * * *$ & $(0.023)$ & & -0.023 & $(0.039)$ \\
\hline Norway & $-0.203 * * *$ & $(0.012)$ & & $-0.252^{* * *}$ & $(0.038)$ \\
\hline Poland & $-0.517 * * *$ & $(0.020)$ & & $-0.785^{* * *}$ & $(0.038)$ \\
\hline Spain & $-0.432 * * *$ & $(0.024)$ & & $-0.780 * * *$ & $(0.035)$ \\
\hline United Kingdom & $-0.275^{* * *}$ & $(0.015)$ & & $-0.430 * * *$ & $(0.039)$ \\
\hline Pseudo- $R^{2}$ & \multirow{2}{*}{\multicolumn{2}{|c|}{$\begin{array}{l}0.041 \\
1,467\end{array}$}} & & \multirow{2}{*}{\multicolumn{2}{|c|}{$\begin{array}{c}0.090 \\
44,149\end{array}$}} \\
\hline Observations & & & & & \\
\hline
\end{tabular}

Note: Probit estimates with robust standard errors:

*** Significant at the 1 percent level.

** Significant at the 5 percent level.

* Significant at the 10 percent level.

characteristics, and $\tilde{\mathbb{F}}_{t}$ are time dummies. Our main variables of interest are the dummies $\tilde{\mathbb{F}}_{c}$ representing the country of origin $c$ of American $j$. These dummies capture the inherited part of civic attitudes transmitted from the country of origin and passed down through generations. We estimate this inherited component and evaluate to what extent inherited attitudes from the country of origin are correlated with current civic attitudes in the home country.

Data on civic attitudes of Americans by country of origin are provided by the General Social Survey database (GSS). This database reports a question on civic attitudes similar to that of the WVS database for two waves, 1991 and 1998. The question reads as follows: "Do you feel it is wrong or not wrong if a person gives the government incorrect information about himself to get government benefits that he is not entitled to." The answer is scaled between one to four for "Not wrong," "A bit wrong," "Wrong," and "Seriously wrong." In line with our classification for the WVS database, we group the answer categories together to represent individuals with strong civic attitudes. Hence, we create a dummy variable which takes on the value one if the respondent answered "Seriously wrong" and zero otherwise. As a robustness check, all the estimations have also been run on the original variables without any significant changes in the results. 


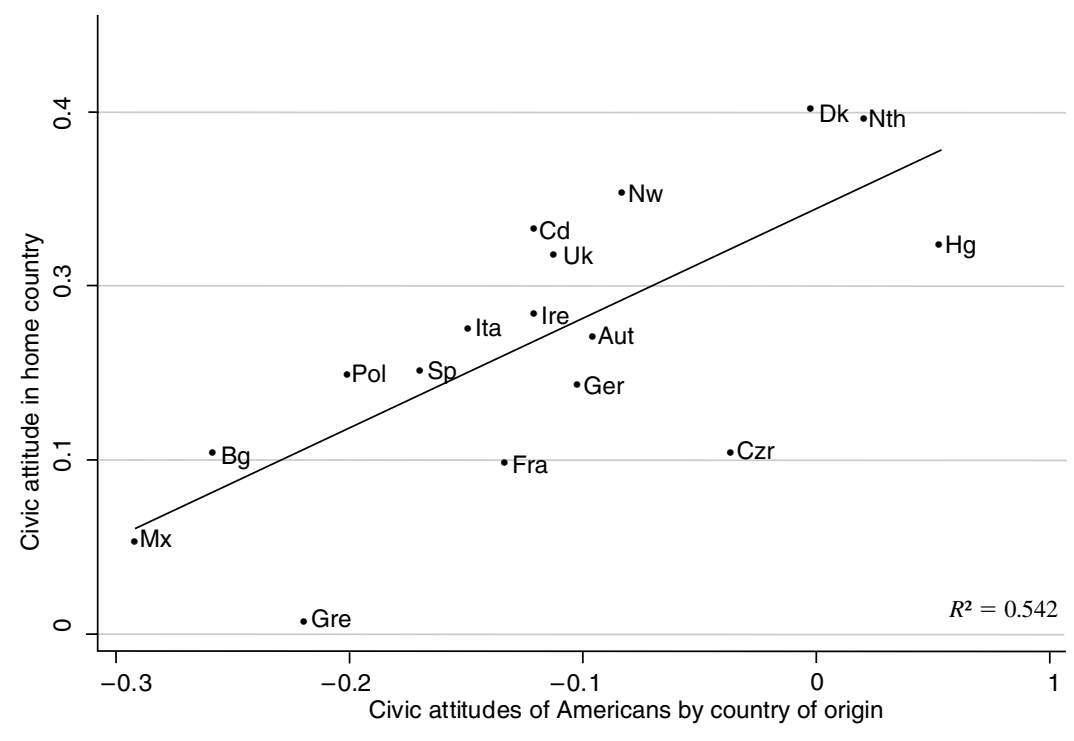

Figure 5

Note: Correlation between civic attitudes of Americans by country of origin and civic attitudes in the home country.

Source: GSS 1991 and 1998, WVS 1990-2000.

The GSS database also reports information on the birth place and the country of origin of the respondent's forebears obtained by the following question: "From what countries or part of the world did your ancestors come from?" Origins cover almost all OECD countries that are referenced in the WVS database. To get interpretable estimates, we select countries of origin with at least 15 observations. This leaves us with the following countries of origin: Austria, Belgium, Canada, Denmark, France, Germany, Greece, Hungary, Ireland, Italy, Mexico, the Netherlands, Norway, Poland, Spain, and the United Kingdom. Civic attitudes by country of origin are calculated as an average on the 1991 and 1998 waves of the General Social Survey ${ }^{[22}$

Table 5 reports the probit estimates of the coefficients $\tilde{\mathbb{F}}_{c}$ and $\mathbb{F}_{c}$ showing up in equations (10) and (8). The explained variable is scaled one if people say that cheating on government benefits is seriously wrong or never justifiable. For estimates in the home countries, we still use the WVS database. We run the estimations on the waves 1990 and 2000 in order to focus on a time period comparable to that of the GSS database. We control for the same set of individual characteristics including age, gender, years of education, income levels, and religious affiliations. Standard errors are corrected for clustering at the country-of-origin level and at the countryof-residency level. Year dummies are included in both regressions. Denmark is considered the reference for the country of Americans ancestry and for the country of residency for respondents in the corresponding home countries.

\footnotetext{
${ }^{22}$ An alternative would have been to separate the estimations for the two different GSS waves in 1991 and late 1998. But due to the limitation of observations by country of origin, we cannot perform separate regressions for the two waves without losing a large amount of country of origins.
} 
Table 5, column 1, reports the estimates of the $\tilde{\mathbb{F}}_{c}$ coefficients. It shows that to have forebearers coming from a different country of origin than Denmark has a sizeable negative effect on the probability of finding it unjustifiable to cheat on government benefits. The effect is always statistically significant. The gap is the most sizeable for Americans with Mexican origins or Mediterranean and Continental European origins. If we compute the marginal coefficients, civic attitudes of Americans with Mexican origins or Greek origins are 29 and 21 percent lower, respectively, than that of Americans with Danish forebears. Respondents with Mediterranean origins from Italy or France come next. Their civic attitudes being 14 and 13 percent lower, respectively, than Americans with Danish origins. Americans whose ancestors came from the United Kingdom, Canada, or Norway also have lower levels of civic attitudes, but the gap for Americans with Danish origins is less significant.

Table 5, column 2 reports the corresponding probit estimates for $\mathbb{F}_{c}$ in the home countries by using the waves 1990 and 2000 of the WVS database. In line with the previous estimates of the entire period 1980-2000, we find that living in Mexico or in the Mediterranean and Continental European countries significantly reduces the level of civic attitudes in comparison to people living in Denmark. The country fixed effects are all significant at the one percent level, with the exception of the Netherlands. The sizes of the coefficients associated with the home country are in general more important than those of the country of origin. But the ordering of countries is fairly similar.

Figure 5 reports the correlation between the marginal effects of the country of origin on the $x$-axis against the marginal effects of the home country on the $y$-axis. The standard error of civic attitudes is much higher across the home country than across the country of origin of Americans. This result suggests that living in the United States has a homogenizing effect on values. But as it happens, the correlation between civic attitudes by country of origin and civic attitudes in the home country is fairly high, with the $R$-squared reaching 54 percent. We also checked the robustness of the results by using the original rank of the civic variable. A strong correlation pattern still holds between civic attitudes of Americans by country of origin and civic attitudes in the home country.

Since the low number of observations for certain countries of origin might be a concern, we check the robustness of our results by using the trust question. For each wave from 1977 to 2002, the GSS database provides a question on trust with exactly the same wording as the one in the WVS database: "Generally speaking, would you say that most people can be trusted or that you need to be very careful in dealing with people?" The answer is given on the same 1-0 scale, the variable being equal to one if the respondents believe in the trustworthiness of others and zero otherwise. Looking at the trust variable during the period of 1977-2002 helps us to increase significantly the number of observations by country of origin, as shown in Appendix D. For instance, we have 118 observations of Americans of Danish origin for the trust variable against 20 observations for the civic variable. In Appendix F, we show that the same strong correlation pattern shows up between inherited trust of Americans by country of origin estimated during the period of 1977-2002, and trust in their home countries estimated in the three waves of the WVS database. The $R$-squared between inherited trust and trust in the home country reaches 0.59 . This 
finding shows that inherited civic attitudes and inherited trust of Americans might be a relevant instrument for the current attitudes in the home country.

IV Regressions of Labor Market Institutions on Civic Attitudes.-We now document the impact of civic attitudes on UB and EP by running the following two-stage regressions:

$$
\begin{gathered}
I_{c t}=\eta_{0}+\eta_{1} \mathbb{F}_{c, t}+\eta_{2} E\left(\boldsymbol{X}_{i t} \mid c\right)+\varepsilon_{c t}, \\
\mathbb{F}_{c, t}=b_{0}+b_{1} E\left(\tilde{a}_{i t} \mid c\right)+b_{2} E\left(\boldsymbol{X}_{i t} \mid c\right)+v_{c t} .
\end{gathered}
$$

Equation (11) is similar to equation (9) where labor market institutions are regressed on civic attitudes. Equation (12) represents the first-stage regression of civic attitudes in the home country on civic attitudes of Americans by country of origin, where $E\left(\tilde{a}_{i t} \mid c\right)$ stands for the average civic attitudes, $\tilde{a}_{i t}$, of Americans whose ancestors came from country $c$.

The left-hand-side variable, $I_{c t}$, represents either unemployment benefits (UB), employment protection (EP), or the ratio UB over EP. We use the OECD indicator on public expenditure per unemployed and the OECD job protection index. We have also checked the robustness of the results by using the composite index of the replacement rate and benefit length. In line with the previous OLS estimates, the results are not modified significantly, but the sample of countries covered by this composite index is smaller.

The control variables of interest are the country fixed effects of civic values in the home country, instrumented by the country of origin fixed effects associated with civic values of Americans. We also account for the additional control variables $E\left(\boldsymbol{X}_{i t} \mid c\right)$, including the average number of years of education of the labor force (educ), the GDP per capita $(g d p k)$, and the degree of openness of the country (openness).

Moreover, we provide a last specification in which we check to what extent the results are not driven by some clustering of countries. In particular, most of the differences in labor market institutions could be driven by the existence of a Mediterranean model characterized by stringent employment protection and low unemployment benefits. Civic attitudes could be statistically significant only to the extent that they pick up North versus South differences. Thus, we include a Mediterranean dummy for France, Italy, Portugal, Spain, and Greece. We also test the robustness with respect to a dummy for Nordic countries without noticeable change. Furthermore, the previous OLS estimates have shown that the relationship between civic attitudes and labor market institutions remain statistically significant when country fixed effects are controlled for ${ }^{23}$

\footnotetext{
${ }^{23}$ A potential concern has to do with the existence of omitted variables. It still might be the case that some national features, such as legal origins and past institutions, which were already at work when people migrated to the United States, could co-determine both civic attitudes of their descendants and current labor market institutions. To control for such omitted variables, ideally, one needs to get some time variation in the instruments for civic attitudes. This time variation would allow the inclusion of country fixed effects in the regression of labor market institutions on civic values and control for any invariant national features. For instance, Algan and Cahuc (2007) show how to exploit the time-variation dimension in inherited social attitudes of Americans to uncover the causal effect of trust on the economic growth of the home countries since the post-war period. Unfortunately, the
} 
Table 6-First-Stage Estimates of Attitudes in the Home Country ON INHERITED AtTitudes OF AMERICANS

\begin{tabular}{lccc}
\hline \hline & $(1)$ & $(2)$ & $(3)$ \\
\hline Panel A: Dependent variable: Civic attitudes in the home country & $1.405^{* * *}$ & $0.710^{* * *}$ & $0.794^{* * *}$ \\
Inherited civic attitudes of Americans & $(0.247)$ & $(0.235)$ & $(0.274)$ \\
$\quad$ from their country of origin & No & Yes*** & Yes*** \\
Controls (openness, gdpk, educ) & No & No & Yes*** \\
Medit. dummy & 0.667 & 0.738 & 0.814 \\
Adjusted $R^{2}$ & 16 & 16 & 16 \\
Number & & & \\
\hline Panel B: Dependent variable: Trust in the home country & $1.331^{* * *}$ & $1.092^{* * * *}$ & $0.923^{* *}$ \\
Inherited trust of Americans & $(0.365)$ & $(0.380)$ & $(0.400)$ \\
$\quad$ from their country of origin & No & Yes & Yes*** \\
Controls (openness, gdpk, educ) & No & No & Yes*** \\
Medit. dummy & 0.411 & 0.483 & 0.514 \\
Adjusted $R^{2}$ & 19 & 19 & 19 \\
Number & & & \\
\hline Panel C: Dependent variable: Trust in the home country & $0.892^{* * *}$ & $0.807^{* * * *}$ & $0.665^{* * *}$ \\
Inherited trust of Americans from their & $(0.227)$ & $(0.216)$ & $(0.226)$ \\
$\quad$ country of origin 1977-1990 \& 1991-2002 & No & Yes & Yes**** \\
Controls (openness, gdpk, educ) & No & No & Yes*** \\
Medit. dummy & 0.594 & 0.645 & 0.671 \\
Adjusted $R^{2}$ & 32 & 32 & 32 \\
Number & & & \\
\hline
\end{tabular}

Table 6, panel A reports the first-stage estimate of civic attitudes in the home country on civic attitudes of Americans by country of origin. Column (1) reports the results of the regression without any controls. Column (2) includes additional controls. Column (3) also includes a Mediterranean dummy. Whatever the specification, there is a positive and statistically significant correlation between inherited civic attitudes and civic attitudes in the home country.

Table 6, panels $\mathrm{B}$ and $\mathrm{C}$ repeat the same first-stage regression, but on trust attitudes. Panel B reports the simple cross-country, first-stage regression. Panel C uses information from the different waves of the WVS and GSS databases. Because the variable trust is documented since 1977 in the GSS database, we have enough information to average the level of trust at two different dates. The GSS surveys from 1977 to 1990 are used to calculate the level of trust in the period ranging from the 1980s to the early 1990s. They are associated with the two waves of the WVS database, 1980 and 1990. Note that we group together the WVS waves 1980 and 1990 to have the largest possible sample of countries over that period, the wave 1980 being less documented. The GSS surveys from 1991 to 2002 are used to calculate the level of trust in the 1990s and 2000s and are associated with the wave 2000 of the WVS database. We have tried different partitions without significant change as long as the number of observations by country of origin was

short time span since UI and EP have been implemented make it impossible to exploit such time variation in civic attitudes. At this point, we focus only on the issue of reverse causality. 
Table 7-Second-Stage Regression of Labor Market Institutions (I)

\begin{tabular}{|c|c|c|c|}
\hline & (1) & (2) & (3) \\
\hline $\begin{array}{l}\text { Panel A: Dependent variable: UB } \\
\text { Civic attitudes } \\
\text { (IV: Inherited civic attitudes of Americans) } \\
\text { Controls (openness, gdpk) } \\
\text { Medit. dummy }\end{array}$ & $\begin{array}{l}0.811^{* * *} \\
(0.248) \\
\text { No } \\
\text { No }\end{array}$ & $\begin{array}{l}0.710 * * * \\
(0.237) \\
\text { Yes*** } \\
\text { No }\end{array}$ & $\begin{array}{l}0.794 * * \\
(0.274) \\
\text { Yes*** } \\
\text { Yes*** }\end{array}$ \\
\hline $\begin{array}{l}\text { Number } \\
\text { Adjusted } R^{2}\end{array}$ & $\begin{array}{c}16 \\
0.404\end{array}$ & $\begin{array}{c}16 \\
0.563\end{array}$ & $\begin{array}{c}16 \\
0.574\end{array}$ \\
\hline $\begin{array}{l}\text { Panel B: Dependent variable: EP } \\
\text { Civic attitudes } \\
\text { (IV: Inherited civic attitudes of Americans) } \\
\text { Controls (openness, gdpk) } \\
\text { Medit. dummy }\end{array}$ & $\begin{array}{c}-2.913^{* *} \\
(1.349) \\
\text { No } \\
\text { No }\end{array}$ & $\begin{array}{l}-2.993 * * \\
(1.370) \\
\text { Yes*** } \\
\text { No }\end{array}$ & $\begin{array}{r}-2.342 \\
(1.509) \\
\text { Yes*** } \\
\text { Yes*** }\end{array}$ \\
\hline $\begin{array}{l}\text { Number } \\
\text { Adjusted } R^{2}\end{array}$ & $\begin{array}{c}16 \\
0.368\end{array}$ & $\begin{array}{c}16 \\
0.478\end{array}$ & $\begin{array}{c}16 \\
0.538\end{array}$ \\
\hline $\begin{array}{l}\text { Panel C: Dependent variable: Ratio UB/EP } \\
\text { Civic attitudes } \\
\text { (IV: Inherited civic attitudes of Americans) } \\
\text { Controls (openness, gdpk) } \\
\text { Medit. dummy }\end{array}$ & $\begin{array}{l}0.585^{* * * *} \\
(0.165) \\
\text { No } \\
\text { No }\end{array}$ & $\begin{array}{l}0.548 * * * \\
(0.156) \\
\text { Yes**** } \\
\text { No }\end{array}$ & $\begin{array}{l}0.551 * * * \\
(0.146) \\
\text { Yes* } \\
\text { Yes*** }\end{array}$ \\
\hline $\begin{array}{l}\text { Number } \\
\text { Adjusted } R^{2}\end{array}$ & $\begin{array}{c}16 \\
0.534\end{array}$ & $\begin{array}{c}16 \\
0.667\end{array}$ & $\begin{array}{c}16 \\
0.667\end{array}$ \\
\hline $\begin{array}{l}\text { Panel D: Dependent variable: Ratio UB/EP } \\
\text { Trust } \\
\text { (IV: Inherited trust of Americans from their }\end{array}$ & $\begin{array}{l}0.900 * * * \\
(0.351)\end{array}$ & $\begin{array}{c}0.876^{* *} \\
(0.384)\end{array}$ & $\begin{array}{r}0.841^{*} \\
(0.500)\end{array}$ \\
\hline $\begin{array}{l}\text { Controls (openness, gdpk) } \\
\text { Medit. dummy }\end{array}$ & $\begin{array}{l}\text { No } \\
\text { No }\end{array}$ & $\begin{array}{l}\text { Yes*** } \\
\text { No }\end{array}$ & $\begin{array}{l}\text { Yes*** } \\
\text { Yes*** }\end{array}$ \\
\hline $\begin{array}{l}\text { Number } \\
\text { Adjusted } R^{2}\end{array}$ & $\begin{array}{c}32 \\
0.147\end{array}$ & $\begin{array}{c}32 \\
0.196\end{array}$ & $\begin{array}{c}32 \\
0.214\end{array}$ \\
\hline
\end{tabular}

approximately equal between the two different samples. This specification also includes period dummies.

Table 6, panels B and C show that the same statistically significant correlation shows up between inherited trust and trust in the home country. In particular, panel $\mathrm{C}$ shows that the correlation is also statistically significant at the 1 percent level when we use two different dates and we increase the number of observations. 24

Table 7 reports the second-stage regression on labor market institutions when we use inherited civic attitudes from the country of origin as an instrument for civic attitudes in the home country. For consistency with the first-stage estimates above, column 1 reports simple estimates without any additional controls. Column 2 includes

\footnotetext{
${ }^{24}$ We have also tried a specification including country fixed effects in order to estimate the correlation between changes in inherited trust in the United States and changes in trust in the home country. The correlation was not statistically significant, however. The most plausible explanation for that result is that the time span of estimation is too short to take into account changes in the transmission of attitudes. Actually, Algan and Cahuc (2007) show that changes in inherited trust are significantly and positively correlated with changes in trust in the home country when we focus on second-generation Americans, and we look at two different cohorts, which do not overlap, by selecting working-age people in the 1950s and the 2000s. We cannot use this strategy here since the institutions $\mathrm{UB}$ and EP have been put in place during a more recent period, mainly during the 1970s.
} 
openness, GDP per capita, and education as additional controls. Column 3 adds also a Mediterranean dummy. For each specification, we find the instrumented values of civicmindedness have a significant impact on UB, EP, and the ratio UB/EP.

To get a sense of the economic impact of civic attitudes on insurance institutions, we run the following counter-factual experiment. We evaluate what would have been the gap in labor market institutions if a different population had inherited the same civic attitudes as the Danish over the period 1980-2003 ${ }^{25}$ This comparison is based on the second-stage estimates including the different controls and dummies. The effects are sizeable. Had the French, the Italians, and the Greeks inherited the same civic attitudes as the Danish, the generosity of unemployment insurance would have been 8.6 percent higher, 9.8 percent higher, and 13.6 percent higher, respectively. Conversely, the stringency of the employment protection legislation would have been 15.8 percent lower in France, 16.6 percent lower in Italy, and 25.9 percent lower in Greece.

Finally, to increase the number of observations, we also look at the second-stage estimates by using the trust variable. To get as many observations as possible, we run these estimates over the two different periods representing the 1980s and the 2000s, as discussed above. The institutions are averaged over the periods 1980-1984 and 2000-2003. Table 7, panel D reports the second-stage regression of labor market institutions when we use inherited trust as an instrument. We find inherited trust has a statistically significant impact on the ratio UB over EP, and the economic effect is of the same order of magnitude as that found with inherited civic attitudes. These results provide tentative evidence of a causal effect of cooperative attitudes, such as civicmindedness and trust, on the design of insurance institutions on the labor market.

\section{Conclusion}

This paper argues that civic virtue is a key ingredient for implementing efficient insurance institutions against labor market risks by lowering the moral hazard issue that plagues unemployment insurance. To that extent civic attitudes could provide an explaination of the observed trade-off between unemployment benefits and employment protection across OECD countries. In countries displaying low levels of civic attitudes towards cheating over government benefits, it is less costly to insure people on the job through employment protection rather than during the unemployment spell with unemployment benefits, even if this choice might be harmful for the efficiency of the labor market.

This paper has focused on public insurance schemes in the labor market. But the logic of the argument might apply to any form of social insurance designed to insure individuals against bad shocks to earnings capacity. In particular, a similar crosscountry pattern holds for public transfers in the health care system, such as disability insurance, that are plagued with moral hazard issues. ${ }^{[26} \mathrm{A}$ promising line of research

\footnotetext{
25 This variation is equal to $\eta_{1} b_{1} E\left(\tilde{a}_{i t} \mid c\right)$, where the coefficients $b_{1}$ is given in the first-stage estimate and corresponds to the coefficients of the second-stage estimate.

${ }^{26}$ Further estimates on the impact of civic attitudes on disability insurance are available upon request.
} 
would be to investigate the role of civic culture in shaping the various dimensions of the welfare state system.

This conclusion raises important questions about the scope of and the instruments for policy reform. Naturally, civic attitudes seem to be persistent, and it might take time to change such attitudes. But growing empirical evidence shows that the institutional and the economic environments can shape civicmindedness and trust in the long run. See Tabellini (2007) for the role of historical institutions or Assar Lindbeck and Sten Nyberg (2006) for the role of parents. Thus, the future of the welfare state systems might depend on the ability of finding adequate policies for fostering civic virtue and social cooperation as shown by Aghion, Algan, and Cahuc (2008).

\section{APPENDIX}

\section{A. The Optimal Policy $(\tau, f, b)$}

The maximization program of the government is

$$
\max _{w, b, X}[1-G(X)] v(w)+G(X) v(b) d H(h)-e,
$$

subject to

$$
\begin{gathered}
\int_{X}^{+\infty}(x-w) d G(x)-G(X) b=k, \\
{[1-G(X)] v(w)+G(X) v(b)-e \geq v(b)-\gamma .}
\end{gathered}
$$

Let us denote the Lagrangian of this program by $\mathcal{L}$ and the Lagrange multipliers associated with contraints (A1) and (A2) by $\mu_{1}$, and $\mu_{2}$, respectively. The first-order conditions read

$$
\frac{\partial \mathcal{L}}{\partial w}=0 \Leftrightarrow v^{\prime}(b)=\mu_{1}+\mu_{2} \frac{1-G(X)}{G(X)} v^{\prime}(b),
$$

and

$$
\frac{\partial \mathcal{L}}{\partial w}=0 \Leftrightarrow X=w-b-[v(w)-v(b)]\left(\frac{1+\mu_{2}}{\mu_{1}}\right) .
$$

The first-order conditions lead us to analyze two cases.

Case 1: $\gamma \geq e$

In that case, $\mu_{2}=0$ implies, according to equations (A5), (A3), and (A4), that $b=w$. When $b=w$ and $\gamma \geq e$, the incentive compatibility constraint (A2) is not 
binding. Therefore, there is full insurance and equation (A5) implies that $X=0$. Then, the free entry condition implies that $w=\int_{0}^{+\infty} x d G(x)-k$.

Case 2: $\gamma<e$

In that case, $\mu_{2}=0$, which still implies, according to equations (A5), (A3), and (A4), that $b=w$, is impossible because the incentive compatibility constraint (A2) cannot be satisfied. Therefore, $\mu_{2}>0$ means that the incentive compatibility constraint (A2) is binding. Equation (A3) can be written as $v^{\prime}(w)=\mu_{1} /\left(1+\mu_{2}\right)$. Substituting this expression into (A5) yields

$$
X=w-b-\frac{v(w)-v(b)}{v^{\prime}(w)} .
$$

Therefore, the optimal value of $(w, X, b)$ is defined by (A6), the zero profit condition (A1), and the binding incentive compatibility constraint (A2). These three equations imply that

$$
v(w)-v(b)=\frac{e-\gamma}{1-G(X)}>0 .
$$

\section{B. Static Comparative Properties of $b$ and $X$}

Let us show that the optimal values of $X$ and $b$ are increasing with respect to $\gamma$ when $\gamma<e$.

The optimal value of $(w, X, b)$ is defined by the zero profit condition:

$$
\int_{X}^{+\infty}(x-w) d G(x)-G(X) b=k
$$

and

$$
\begin{gathered}
X=w-b-\frac{v(w)-v(b)}{v^{\prime}(w)} . \\
v(w)-v(b)=\frac{e-\gamma}{1-G(X)}>0 .
\end{gathered}
$$

The zero profit condition (B7) implicitly defines $w$ as a function of $X$ and $b$. Let us denote by $w(X, b)$ this function, for which the partial derivatives are

$$
\begin{gathered}
\frac{\partial w(X, b)}{\partial X}=\frac{G^{\prime}(X)}{1-G(X)}(w-X-b), \\
\frac{\partial w(X, b)}{\partial b}=\frac{-G(X)}{1-G(X)} .
\end{gathered}
$$


TABle 8-SAmple of Countries in WVS and GSS

\begin{tabular}{|c|c|c|c|}
\hline & $\begin{array}{c}\text { WVS } \\
1980,1990,2000\end{array}$ & $\begin{array}{c}\text { GSS: Surveys on civicness } \\
1919 \text { and } 1998\end{array}$ & $\begin{array}{c}\text { GSS: Surveys on trust } \\
1977-2002\end{array}$ \\
\hline Country & Observations & Observations & Observations \\
\hline Australia & 3,131 & - & - \\
\hline Austria & 2,840 & 16 & 84 \\
\hline Belgium & 5,508 & 15 & 19 \\
\hline Canada & 4,844 & 56 & 339 \\
\hline Czech Republic & 2,790 & 24 & 214 \\
\hline Denmark & 2,807 & 20 & 118 \\
\hline France & 3,725 & 54 & 344 \\
\hline Germany & 5,382 & 341 & 3,034 \\
\hline Greece & 1,107 & 12 & 51 \\
\hline Hungary & 3,311 & 16 & 89 \\
\hline Ireland & 3,199 & 246 & 2,067 \\
\hline Italy & 5,328 & 116 & 870 \\
\hline Japan & 3,378 & - & - \\
\hline Mexico & 4,761 & 77 & 367 \\
\hline Netherlands & 3,038 & 32 & 266 \\
\hline Norway & 3,558 & 33 & 311 \\
\hline Poland & 1,998 & 62 & 476 \\
\hline Portugal & 2,168 & - & - \\
\hline Spain & 8,778 & 19 & 111 \\
\hline Sweden & 2,854 & - & 274 \\
\hline Switzerland & 2,491 & - & - \\
\hline United Kingdom & 3,573 & 381 & 2,793 \\
\hline United States & 5,242 & - & - \\
\hline
\end{tabular}

Table 9-Summary Statistics IN WVS and GSS

\begin{tabular}{lccccc}
\hline \hline & \multicolumn{2}{c}{ WVS } & & \multicolumn{2}{c}{ GSS } \\
\cline { 2 - 3 } \cline { 5 - 6 } Variables & Mean & Std. Dev. & & Mean & Std. Dev. \\
\cline { 2 - 3 } Men & 0.481 & 0.5 & & 0.45 & 0.49 \\
Age & 42.807 & 17.278 & & 45.78 & 17.72 \\
Age education & 17.317 & 3.582 & & 13.04 & 2.80 \\
Low-income & 0.426 & 0.494 & & 0.467 & 0.492 \\
Mid-income & 0.339 & 0.473 & & 0.5 & 0.5 \\
Up-income & 0.236 & 0.498 & & 0.032 & 0.178 \\
Catholic & 0.413 & 0.492 & & 0.304 & 0.460 \\
Protestant & 0.322 & 0.467 & & 0.591 & 0.491 \\
Muslim & 0.043 & 0.202 & & 0.00 & 0.00 \\
Jewish & 0.005 & 0.074 & & 0.010 & 0.103 \\
Buddhist & 0.025 & 0.155 & & 0.001 & 0.035 \\
Others & 0.025 & 0.155 & & & 0.289 \\
No religion & 0.168 & 0.374 & & 0.092 & 0.289 \\
\hline
\end{tabular}

When $w=w(X, b)$, the differentiation of equations (B8) and (B9) with respect to $X, b$, and $\gamma$ yields

$$
\frac{d b}{d \gamma}=\frac{1}{G(X) v^{\prime}(w)+[1-G(X)] v^{\prime}(b)}>0,
$$




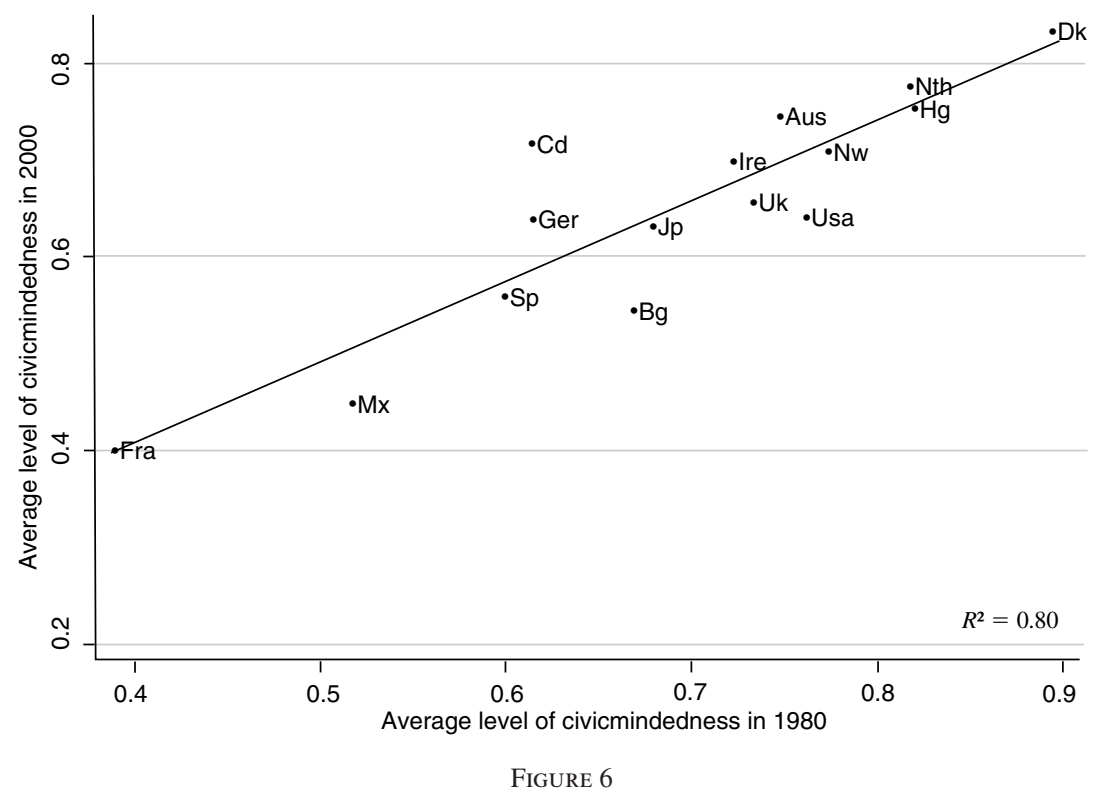

Notes: Mean reply to the question: "Do you think it can always be justified, never be justified or something in between to claim government/state benefits to which you have no rights." The score associated with the answer "never" is 1 . The score of other answers is 0 .

Source: WVS 1980, 2000.

(B11)

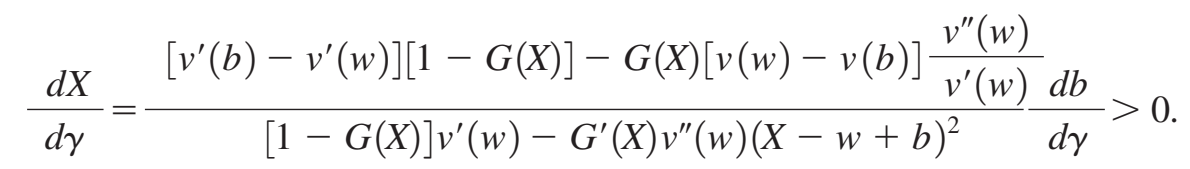

The last equation is positive because $v$ is concave, and $w>b$ when $\gamma<e$.

\section{Data on Attitudes}

Summary Statistics.-Table 8 lists the sample of countries used in the WVS database and the GSS database. Table 9 shows the main individual characteristics of the respondents in these two surveys. The variable "Age" is expressed in years. The variable "Education" is the age at which the respondent completed her highest education. The variable "Income" derives from the question: "Here is a scale of incomes. We would like to know in what group your household is, counting all wages, salaries, pensions and other income that come in." The answers in the databases are scaled $1-10$. We constructed three categories: low income (1st-3rd deciles), mean income (4th-6th deciles) and high income (7th-10th deciles).

Evolution of Civic Attitudes.-Figure 6 reports the persistence of civic attitudes over time. It turns out that there is a strong correlation, within each country, 27

\footnotetext{
${ }^{27}$ The WVS provides information for only 15 countries among our selected sample in 1980 .
} 


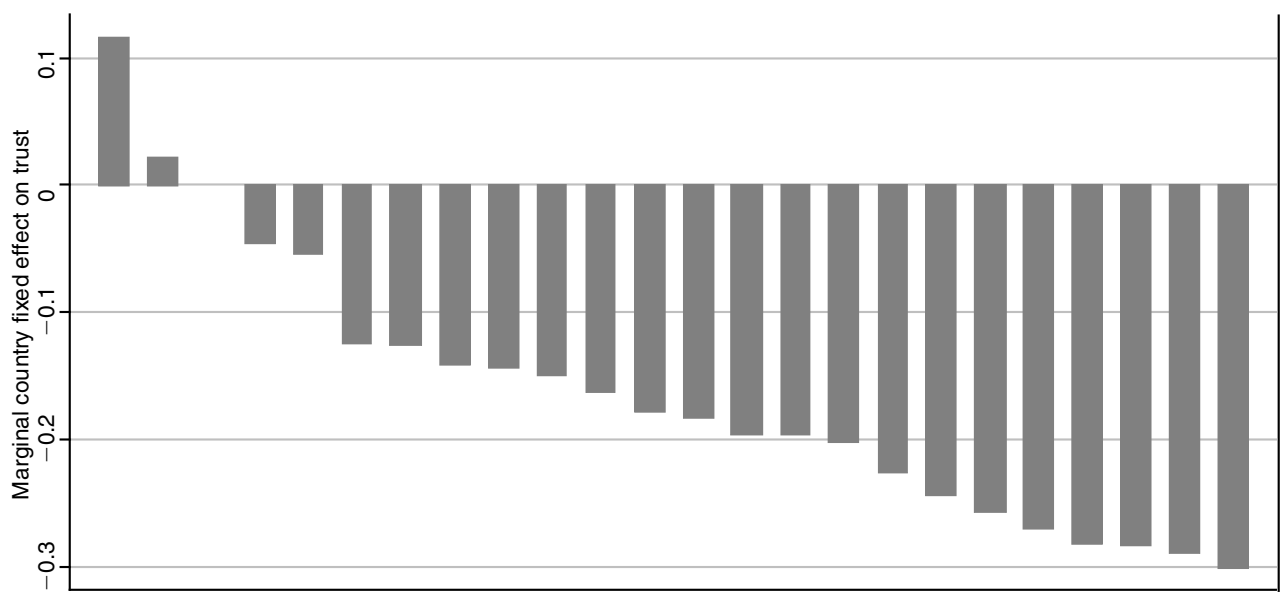

Nw Swd Dk Fin Nth Ire Cd Uk Jp Aus Usa Ger Sp Ita Aut Switz Bg Mx Czr Hg Pol Fra Gre Pt

FIGURE 7

Notes: Marginal country effects associated with the question: "Generally speaking, would you say that most people can be trusted or that you need to be very careful in dealing with people?" The score associated with the answer "yes" is 1 , and 0 otherwise.

Source: WVS 1980, 1990, 2000.

between the share of people who think that it is never justifiable to cheat on government benefits in the 1980 and 2000 waves. Accordingly, the ordering of countries with regard to civic attitudes remains stable over time.

Cross-country Heterogeneity in Trust.-Figure 7 presents the marginal country fixed effect on the probability that the respondent answers yes to the question: "Generally speaking, would you say that most people can be trusted or that you need to be very careful in dealing with people?" We run probit estimates on the 1-0 trust variable covering the three waves by including country fixed effects and controlling for the same set of individual characteristics as we did for the civic variable. Denmark is still considered as the reference country.

\section{Data on Unemployment Insurance and Employment Protection}

We report cross-country evidence on the heterogeneity in unemployment benefits and employment protection. The different institutions are averaged over the period 1980-2000. We also report the basic correlation with the country level of civic attitudes captured by the marginal coefficients of the country fixed effect in the probit regression of the 1-0 civic variable. This regression is run by pooling the three waves of the WVS database.

Figure 8 shows a strong positive correlation between expenditure per unemployed and civic attitudes. In general, Nordic countries tend to have higher civic attitudes and higher levels of expenditure per unemployed, while the correlation is the other way around for Mediterranean countries like Greece, France, and 


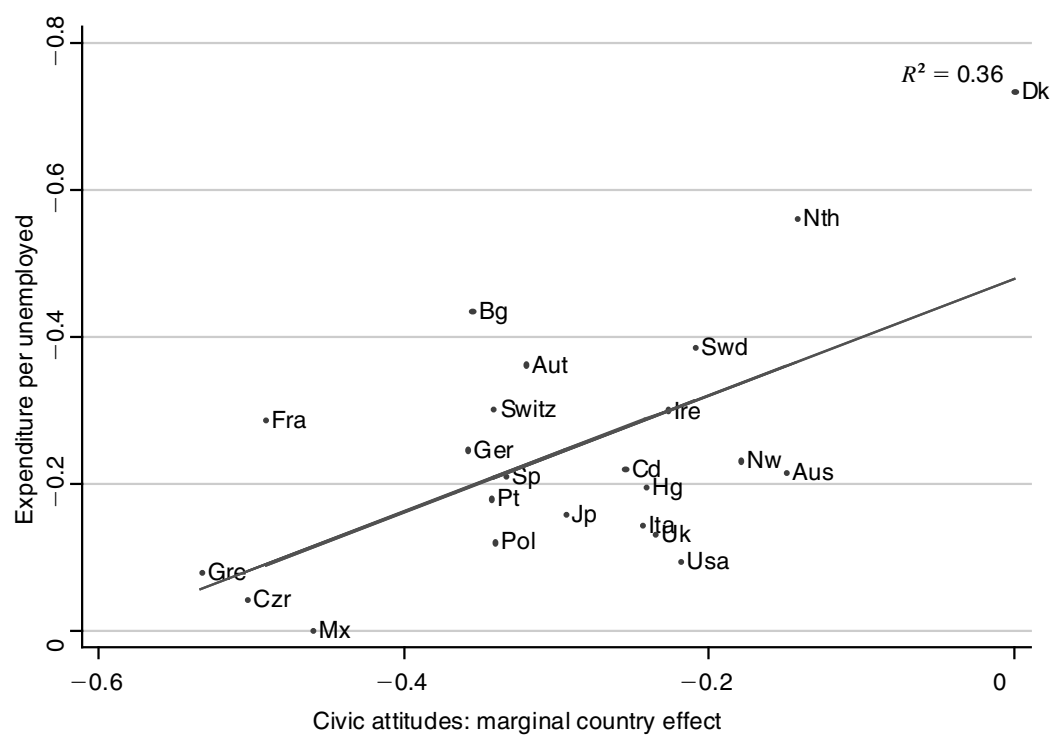

FIGURE 8

Notes: Correlation between civic attitudes and the ratio of public expenditure per unemployed. Civic attitudes are proxied by the estimated marginal country fixed effects in the probit regression of the question "Do you think it is unjustifiable to cheat on government benefits."

Source: OECD and WVS database 1980-2000.

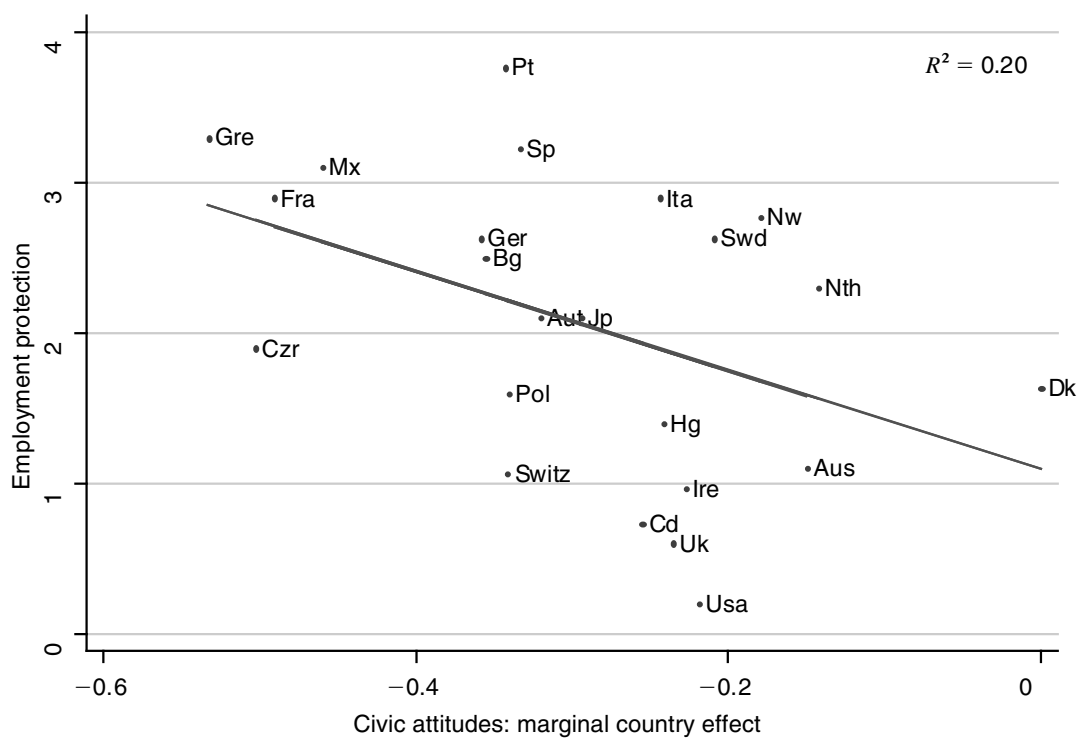

FIGURE 9

Notes: Correlation between civic attitudes and employment protection. Civic attitudes are proxied by the estimated marginal country fixed effects in the probit regression of the question "Do you think it is unjustifiable to cheat on government benefits."

Source: OECD and WVS database 1980-2000. 


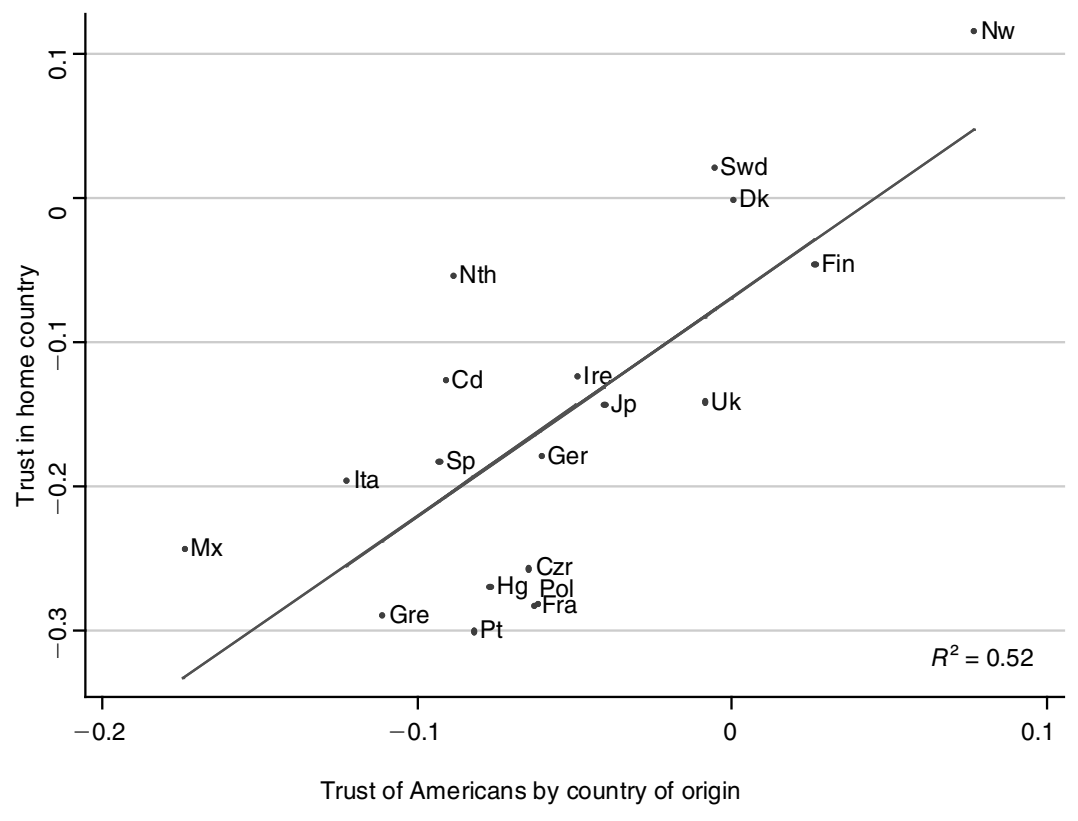

FiguRE 10

Note: Correlation between trust of Americans by country of origin and trust in the home countries.

Source: GSS 1977-2002 and WVS 1980-2000.

Spain. This first rough picture shows that 36 percent of the cross-country heterogeneity in public expenditure per unemployed is associated with the heterogeneity in national civic attitudes. Figure 9 repeats the same exercise with respect to employment protection. A negative correlation shows up between the stringency of employment protection and national civic attitudes over that period. Mediterranean and Continental European countries tend to have both low civic attitudes and high employment protection legislation, while the reverse holds true for Nordic countries. The Anglo-Saxon countries stand a little apart from these two pictures since they have less employment protection and fewer unemployment benefits. Yet, by looking at the ratio of UB over EP reported in Figure 3, the Anglo-Saxon countries turn out to be much closer to the Nordic countries with which they share higher civic values.

\section{E. Trust of Americans}

This section reports the probit estimates on the 1-0 trust dummy by controlling for the same individual characteristics as we did for the regression on the civic variable. The probit estimation is carried on the three waves 1980, 1990, and 2000 for the WVS database and on the waves since 1977 of the GSS database. Figure 10 reports the marginal effect associated with the country of residency on the $y$-axis against the marginal effect associated with the country of origin of Americans on 
the $x$-axis. As it happens, a fairly high correlation pattern shows up between trust of Americans by country of origin and trust in their home countries, with the $R$-squared reaching 0.52 .

\section{REFERENCES}

Agell, Jonas. 2000. "On the Determinants of Labour Market Institutions: Rent-Sharing vs. Social Insurance." CESifo Working Paper 384.

Aghion, Philippe, Yann Algan, and Pierre Cahuc. 2008. "How can policy influence culture? Minimum wage and the Quality of Labor Relations." Unpublished.

Alesina, Alberto, and Edward L. Glaeser. 2004. Fighting Poverty in the US and Europe. Oxford: Oxford University Press.

Alesina, Alberto, Edward L. Glaeser, and Bruce Sacerdote. 2005. "Work and Leisure in the U.S. And Europe: Why So Different?" National Bureau of Economic Research Working Paper 11278.

Algan, Yann, and Pierre Cahuc. 2005. "The Roots of Low European Employment: Family Culture?" NBER International Macroeconomics Annual, ed J. Frenkel and C. Pissarides, 65-109. Cambridge, MA: MIT Press.

Algan, Yann, and Pierre Cahuc. 2007. "Social Attitudes and Economic Development: An Epidemiological Approach.” IZA Discussion Paper 2935.

Almond, Gabriel A., and Sidney Verba. 1963. The Civic Culture: Political Attitudes and Democracy in Five Nations. Princeton, NJ: Princeton University Press.

Antecol, Heather. 2000. "An Examination of Cross-Country Differences in the Gender Gap in Labor Force Participation Rates." Labour Economics, 7(4): 409-26.

-Azariadis, Costas. 1975. "Implicit Contract and Underemployment Equilibria". Journal of Political Economy, 83(6): 1183-1202.

-Baily, Martin Neil. 1974. "Wages and Employment under Uncertain Demand." Review of Economic Studies, 41(1): 37-50.

Banfield, Edward C. 1958. The Moral Basis of a Backward Society. New York: Free Press.

-Blanchard, Olivier. 2004. "The Economic Future of Europe." Journal of Economic Perspectives, 18(4): 3-26.

Blanchard, Olivier, and Thomas Philippon. 2004. "The Quality of Labor Relations and Unemployment." National Bureau of Economic Research Working Paper 10590.

Blanchard, Olivier, and Jean Tirole. 2004. "The Optimal Design of Unemployment Insurance and Employment Protection. A First Pass." National Bureau of Economic Research Working Paper 10443.

Boeri, Tito, J. Ignacio Conde-Ruiz, and Vincenzo Galasso. 2004. "Cross-Skill Redistribution and the Tradeoff between Unemployment Benefits and Employment Protection." IZA Discussion Paper 1371.

Burdett, Kenneth, and Randall Wright. 1989a. "Optimal Firm Size, Taxes, and Unemployment." Journal of Public Economics, 39(3): 275-87.

Burdett, Kenneth, and Randall Wright. 1989b. "Unemployment Insurance and Short-Time Compensation: The Effects on Layoffs, Hours Per Worker, and Wages." Journal of Political Economy, 97(6): 1479-96.

Chiu, W. Henry, and Edi Karni. 1998. "Endogenous Adverse Selection and Unemployment Insurance." Journal of Political Economy, 106(4): 806-27.

Feldstein, Martin S. 1976. "Temporary Layoffs in the Theory of Unemployment." Journal of Political Economy, 84(5): 937-57.

Fernández, Raquel. 2008. "Culture and Economics." In New Palgrave Dictionary of Economics. 2nd ed., ed. Steven N. Durlauf and Lawrence E. Blume. New York: Palgrave Macmillan.

Fernández, Raquel, and Allesandra Fogli. 2005. "Culture: An Empirical Investigation of Beliefs, Work, and Fertility." Federal Reserve Bank of Minneapolis Research Department Staff Report 361.

- Fernández, Raquel, Alessandra Fogli, and Claudia Olivetti. 2004. "Mothers and Sons: Preference Formation and Female Labor Force Dynamics." Quarterly Journal of Economics, 119(4): 1249-99.

Freeman, Richard B. 2000. "Single Peaked vs. Diversified Capitalism: The Relation between Economic Institutions and Outcomes." National Bureau of Economic Research Working Paper 7556.

Freeman, Richard B., and Ronald Schettkat. 2005. "Marketization of Household Production and the EU-US Gap in Work." Economic Policy, 20(41): 5-39.

-Giuliano, Paola. 2007. "Living Arrangements in Western Europe: Does Cultural Origin Matter?" Journal of the European Economic Association, 5(5):927-52. 
Guiso, Luigi, Paola Sapienza, and Luigi Zingales. 2004. "The Role of Social Capital in Financial Development." American Economic Review, 94(3): 526-56.

-Ichino, Andrea, and Giovanni Maggi. 2000. "Work Environment and Individual Background: Explaining Regional Shirking Differentials in a Large Italian Firm." Quarterly Journal of Economics, 115(3): 1057-90.

Kiander, Jaakko. 1993. "Endogenous Unemployment Insurance in a Monopoly Union Model When Job Search Matters." Journal of Public Economics, 52(1): 101-15.

Knack, Stephen, and Philip Keefer. 1997. "Does Social Capital Have an Economic Payoff? A CrossCountry Investigation.” Quarterly Journal of Economics, 112(4): 1251-88.

Lindbeck, Assar, and Sten Nyberg. 2006. "Raising Children to Work Hard: Altruism, Work Norms, and Social Insurance." Quarterly Journal of Economics, 121(4): 1473-1503.

Nickell, Stephen, Luca Nunziata, Wolfgang Ochel, and Glenda Quintini. 2001. "The Beveridge Curve, Unemployment and Wages in the Oecd from the 1960s to the 1990s." LSE Discussion Paper 0502.

Persson, Torsten, and Guido Tabellini. 2000. Political Economics: Explaining Economic Policy. Cambridge, MA: MIT Press.

Putnam, Robert D. 1993. Making Democracy Work: Civic Traditions in Modern Italy. Princeton, NJ: Princeton University Press.

Rice, Tom W., and Jan Feldman. 1997. "Civic Culture and Democracy from Europe to America." The Journal of Politics, 59(4): 1143-72.

Rogerson, Richard. 2003. "Structural Transformation and the Deterioration of European Labor Market Outcomes." National Bureau of Economic Research Working Paper 128889.

Tabellini, Guido. 2005. "Culture and Institutions: Economic Development in the Regions of Europe." Bocconi University Innocenzo Gasparini Institute for Economic Research Working Paper 292.

Tabellini, Guido. 2007. "Culture and Institution.” Marshall lecture EEA, IGIER Working Paper 330. 


\section{This article has been cited by:}

1. Dimitris Georgarakos, Sven Fürth. 2014. Household repayment behavior: The role of social capital and institutional, political, and religious beliefs. European Journal of Political Economy . [CrossRef]

2. Giacomo Corneo, Frank Neher. 2014. Income inequality and self-reported values. The Journal of Economic Inequality 12:1, 49-71. [CrossRef]

3. Olivier J Blanchard, Florence Jaumotte, Prakash Loungani. 2014. Labor market policies and IMF advice in advanced economies during the Great Recession. IZA Journal of Labor Policy 3:1, 2. [CrossRef]

4. Yann Algan, Pierre CahucTrust, Growth, and Well-Being: New Evidence and Policy Implications 49-120. [CrossRef]

5. Maria Krambia-Kapardis. 2013. Perception of political corruption as a function of legislation. Journal of Financial Crime 21, 44-55. [CrossRef]

6. Jean-Baptiste Michau. 2013. UNEMPLOYMENT INSURANCE AND CULTURAL TRANSMISSION: THEORY AND APPLICATION TO EUROPEAN UNEMPLOYMENT. Journal of the European Economic Association 11:6, 1320-1347. [CrossRef]

7. Claus-Jochen Haake, Tim Krieger, Steffen Minter. 2013. On the institutional design of burden sharing when financing external border enforcement in the EU. International Economics and Economic Policy 10:4, 583-612. [CrossRef]

8. Giacomo Corneo. 2013. Work norms, social insurance and the allocation of talent. Journal of Public Economics 107, 79-92. [CrossRef]

9. Christian Bjørnskov, Gert Tinggaard Svendsen. 2013. Does social trust determine the size of the welfare state? Evidence using historical identification. Public Choice 157:1-2, 269-286. [CrossRef]

10. Eiji Yamamura. 2013. Trust in government and its effect on preferences for income redistribution and perceived tax burden. Economics of Governance . [CrossRef]

11. Niklas Potrafke. 2013. Globalization and labor market institutions: International empirical evidence. Journal of Comparative Economics 41:3, 829-842. [CrossRef]

12. Tommaso Nannicini,, Andrea Stella,, Guido Tabellini,, Ugo Troiano. 2013. Social Capital and Political Accountability. American Economic Journal: Economic Policy 5:2, 222-250. [Abstract] [View PDF article] [PDF with links]

13. Aitor Calo-Blanco, J. Ignacio García-Pérez. 2013. On the welfare loss caused by inequality of opportunity. The Journal of Economic Inequality . [CrossRef]

14. Holger Stichnoth, Karine Van der Straeten. 2013. ETHNIC DIVERSITY, PUBLIC SPENDING, AND INDIVIDUAL SUPPORT FOR THE WELFARE STATE: A REVIEW OF THE EMPIRICAL LITERATURE. Journal of Economic Surveys 27:2, 364-389. [CrossRef]

15. Noel Gaston, Gulasekaran Rajaguru. 2013. International migration and the welfare state revisited. European Journal of Political Economy 29, 90-101. [CrossRef]

16. Ingmar Schumacher. 2013. Political stability, corruption and trust in politicians. Economic Modelling 31, 359-369. [CrossRef]

17. Tomer Blumkin, Yoram Margalioth, Efraim Sadka. 2013. The desirability of workfare in the presence of misreporting. International Tax and Public Finance 20:1, 71-88. [CrossRef]

18. Daniel Arnold. 2013. Benefit Morale and Cross-Country Diversity in Sick Pay Entitlements. Kyklos 66:1, 27-45. [CrossRef] 
19. Yann Algan, Pierre Cahuc. 2013. Trust and Growth. Annual Review of Economics 5:1, 521-549. [CrossRef]

20. HUGO J. FARIA, DANIEL R. MORALES, NATASHA PINEDA, HUGO M. MONTESINOS. 2012. Can capitalism restrain public perceived corruption? Some evidence. Journal of Institutional Economics 8:04, 511-535. [CrossRef]

21. C. Young. 2012. Losing a Job: The Nonpecuniary Cost of Unemployment in the United States. Social Forces 91:2, 609-634. [CrossRef]

22. Florian Baumann, Tobias Brändle. 2012. Self-employment, educational attainment and employment protection legislation. Labour Economics 19:6, 846-859. [CrossRef]

23. Dalit Contini, Matteo G. Richiardi. 2012. Reconsidering the effect of welfare stigma on unemployment. Journal of Economic Bebavior \& Organization 84:1, 229-244. [CrossRef]

24. Tito Boeri, J. Ignacio Conde-Ruiz, Vincenzo Galasso. 2012. THE POLITICAL ECONOMY OF FLEXICURITY. Journal of the European Economic Association 10:4, 684-715. [CrossRef]

25. Paolo Pinotti. 2012. Trust, Regulation and Market Failures. Review of Economics and Statistics 94:3, 650-658. [CrossRef]

26. Roland Iwan Luttens, Marie-Anne Valfort. 2012. Voting for Redistribution under DesertSensitive Altruism*. The Scandinavian Journal of Economics no-no. [CrossRef]

27. Björn Brügemann. 2012. DOES EMPLOYMENT PROTECTION CREATE ITS OWN POLITICAL SUPPORT?. Journal of the European Economic Association no-no. [CrossRef]

28. Beatrix Eugster, Rafael Lalive, Andreas Steinhauer, Josef Zweimüller. 2011. The Demand for Social Insurance: Does Culture Matter?*. The Economic Journal 121:556, F413-F448. [CrossRef]

29. Karla Hoff, Mayuresh Kshetramade, Ernst Fehr. 2011. Caste and Punishment: the Legacy of Caste Culture in Norm Enforcement*. The Economic Journal 121:556, F449-F475. [CrossRef]

30. L. Rachel Ngai,, Christopher A. Pissarides. 2011. Taxes, Social Subsidies, and the Allocation of Work Time. American Economic Journal: Macroeconomics 3:4, 1-26. [Abstract] [View PDF article] [PDF with links]

31. Eiji Yamamura. 2011. Government Size and Trust. Review of Social Economy 1-26. [CrossRef]

32. Kjell Erik Lommerud, Odd Rune Straume. 2011. Employment Protection Versus Flexicurity: On Technology Adoption in Unionised Firms*. The Scandinavian Journal of Economics no-no. [CrossRef]

33. Bruno Decreuse, Tanguy van Ypersele. 2011. Housing market regulation and the social demand for job protection. Journal of Public Economics . [CrossRef]

34. Andreas Bergh, Christian Bjørnskov. 2011. Historical Trust Levels Predict the Current Size of the Welfare State. Kyklos 64:1, 1-19. [CrossRef]

35. Boeri TitoInstitutional Reforms and Dualism in European Labor Markets 1173-1236. [CrossRef]

36. Alberto Bisin, Thierry VerdierThe Economics of Cultural Transmission and Socialization 339-416. [CrossRef]

37. Yann Algan,, Pierre Cahuc. 2010. Inherited Trust and Growth. American Economic Review 100:5, 2060-2092. [Abstract] [View PDF article] [PDF with links]

38. Niklas Potrafke. 2010. Labor market deregulation and globalization: empirical evidence from OECD countries. Review of World Economics 146:3, 545-571. [CrossRef] 